\title{
TNF- $a$ Increase the Risk of Bleeding in Patients after CAR-T Cell Therapy: A Bleeding Model Based on a Real-World Study of Chinese Car-T Working Party
}

Jiaqian Qi

First Affiliated Hospital of Soochow University

Xin Lv

First Affiliated Hospital of Soochow University

Jia Chen

First Affiliated Hospital of Soochow University

Hong Wang

First Affiliated Hospital of Soochow University

Tiantian Chu

First Affiliated Hospital of Soochow University

\section{Yaqiong Tang}

First Affiliated Hospital of Soochow University

Tingting Pan

First Affiliated Hospital of Soochow University

Meng Zhou

First Affiliated Hospital of Soochow University

Chengsen Cai

First Affiliated Hospital of Soochow University

\section{Yuan Ren}

PLAGH: Chinese PLA General Hospital

\section{Yuejun Liu}

First Affiliated Hospital of Soochow University

Yi Fan

First Affiliated Hospital of Soochow University

\section{Wenhong Shen}

First Affiliated Hospital of Soochow University

\section{Xiao Ma}

First Affiliated Hospital of Soochow University

\section{Huiying Qiu}

First Affiliated Hospital of Soochow University

Xiaowen Tang 
First Affiliated Hospital of Soochow University

\section{Chengcheng Fu}

First Affiliated Hospital of Soochow University

\section{Depei Wu}

First Affiliated Hospital of Soochow University

\section{Yue Han ( $\sim$ hanyue@suda.edu.cn )}

First Affiliated Hospital of Soochow University https://orcid.org/0000-0002-7560-7195

\section{Research}

Keywords: CAR T-cell therapy, Bleeding, Cytokine-release syndrome, TNF-a, Prediction model

Posted Date: November 19th, 2020

DOl: https://doi.org/10.21203/rs.3.rs-108274/v1

License: (c) (i) This work is licensed under a Creative Commons Attribution 4.0 International License. Read Full License 


\section{Abstract}

Backgroud: Chimeric antigen receptor (CAR) T-cell therapy has shown excellent clinical efficacy in patients with hematologic malignancies. However, severe bleeding after this treatment is a lifethreatening complication for most patients.

Objectives: This study evaluated the risk factors associated with bleeding in CAR-T treatment and developed a predictive model for this complication.

Methods: We conducted a real-world study incorporating data from 400 patients with hematologic malignancies treated with CAR-T between November 1, 2015 and September 1, 2019. Also 39 patients from another hospital were selected for external validation.

Results: Patients with severe bleeding (hazard ratio [HR] 13.04, 95\% confidence interval [Cl] 5.82-29.18; $\mathrm{p}<0.001$ ) had a higher risk of death after CAR-T. Stage III and IV cytokine release syndrome (CRS) (odds ratio [OR] 6.07, 95\% $\mathrm{Cl} 2.35-16.76 ; p<0.001)$ and higher tumor necrosis factor-a (TNF-a) levels (OR 4.00, $95 \% \mathrm{Cl} 1.53-11.35 ; \mathrm{p}<0.001)$ were independent factors of bleeding in patients after CAR-T treatment. The predictive model developed by Lasso regression, which selected factors such as CRS period, transfusion volume, platelet percentage, platelet count, thrombinogen time, interleukin 6 and TNF-a levels, and showed Nomogram, yielded excellent agreement (C-statistics=0.905) with the calibration curve, which improved clinical benefit with respect to established bleeding scores such as outpatient bleeding risk index (MOBRI). External validation was performed using 39 patients from another hospital with an AUC of 0.700 .

Conclusions: Patients with severe bleeding after Car-T therapy had increased the risk of death. A crossvalidated bleeding risk score based on CRS stages and TNF-a level show significant prognostic value in patients undergoing Car-T treatment.

\section{Introduction}

Advances in chimeric antigen receptor (CAR) T-cell therapy have revolutionized the treatment of hematologic malignancies, especially in relapsed and refractory patients[1]. Anti-cell differentiation 19 (CD19)-directed CAR T-cell therapy is effective and safe in non-Hodgkin lymphoma (NHL) [2] and is also useful in patients with relapsed and refractory acute lymphoblastic leukemia (ALL) [3, 4]. CAR T-cell therapy has also shown efficacy in patients with acute myeloid leukemia (AML)[5] and multiple myeloma (MM)[6]. However, associated toxicity, particularly cytokine release syndrome (CRS) and hemorrhagic events, limit the prognosis of patients receiving this treatment[7]. Hemorrhagic diseases including partial thromboplastin time (PTT) [3, 4] and prolonged thromboplastin time (PT) (PT)[3], disseminated intravascular coagulation (DIC)[8], and fibrinogen reduction often occur during treatment[3, 6]. Bleeding events associated with CAR T-cell therapy can lead to patient death[9], although these events have a multifactorial cause and the contribution of CAR T-cell infusion is unknown. 
CRS is an inflammatory process that occurs as a result of high levels of immune activation[10], and the level of immune activation required for modern immunotherapy to mediate clinical benefit exceeds that which occurs in more natural settings[11], Inflammation-related hemostasis occurs in many diseases[12]. Inflammation and severe infection inevitably cause hemostatic abnormalities, ranging from inconspicuous laboratory changes to severe DIC[13]. Inflammation and coagulation as a response to acute infection manifests itself in the most extreme forms of multiple organ failure and DIC, the correlation of which is becoming increasingly clear $[14,15]$. Cytokines, especially tumor necrosis factor-a (TNF- $a$ ) and interleukin-6 (IL-6) are increased during CRS[16], which may be associated with inflammation-related hemostasis. However, the association between CRS, TNF-a and bleeding during CAR T-cell therapy is unclear.

To determine the role of bleeding in patients receiving CAR T-cell therapy and to elucidate risk factors for this complication, we conducted a single-center real-world study in a Chinese population. The prognostic value of bleeding was determined using multivariate adjusted survival analysis. Subsequently, we obtained a multivariate scoring model to predict the prognostic value of CAR T-cell therapy-related bleeding, which was validated using a logistic regression model. In addition, the prognostic value of the bleeding risk score was also confirmed. The validation cohort included a separate series of 39 patients from another hospital.

\section{Methods}

\section{Study design and participants}

We conducted a real-world study incorporating data from 400 patients with hematologic malignancies who underwent continuous CAR T treatment at the First Affiliated Hospital of Suzhou University (Jiangsu, China) between November 1, 2015 and January 1, 2019. The end date of the follow-up visit is September 1 , 2019. The validation cohort consisted of an independent series of 39 patients from Hongci Hematology Hospital. Patient data were collected in accordance with the standards for registration tracking (NCT03919240). Patients who were on antithrombotic therapy, had severe renal or hepatic insufficiency or hemorrhagic disease, lacked information on bleeding complications or had no follow-up information were excluded. A flowchart of the patient enrollment process is shown (Figure 1). Electronic medical records are used to obtain demographic variables. Gender; sex; age; diagnosis; percentage of vesicle cells in bone marrow; type of CAR T cell therapy; application of IL-6 knockout; hypertension and diabetes status; CAR T cell count; CRS staging; use of hematopoietic stem cell transplantation (HSCT); efficacy (complete remission); transfusion application; DIC incidence; platelet count before and after CAR T cell therapy; white blood cell count; hemoglobin levels. Active partial thrombinogen time (APTT); thrombinogen time (PT); thrombinogen time (TT); IL-2, IL-4, IL-6, IL-6, IL-10, IL-17A, TNF-a, and interferon gamma (IFN- $\gamma$ ) levels. Bleeding risk was estimated from modified outpatient bleeding risk index (MOBRI) and levels of hypertension, abnormal renal/hepatic function, stroke, history or susceptibility to bleeding, IL-2-4, IL-6, IL-10, TNF-17A, TNF- $a$ and IFN- $\gamma$; as well as bleeding site and bleeding grade. Details of the above variants are given in Part III of the supplementary information. The mortality data are derived from 
the hospital death registers, and the time of death is confirmed through access to electronic medical records or telephone follow-up visits. The median follow-up time was 9.2 months. The creation of the database was carried out by an independent researcher who was not involved in the care of the patients. Informed consent was obtained from all patients or their immediate family members. All research programmes are in line with the guidelines of the Ethics Committee of Soochow University and follow the Declaration of Helsinki.

\section{CRS grading system}

The CRS stage was evaluated by the CAR T-cell therapy-associated TOXicity Working Group[17]. Grade 1 organ toxicities were: temperature $\geq 38.0^{\circ} \mathrm{C}$, systolic blood pressure $\geq 90 \mathrm{mmHg}$, and arterial oxygen saturation $>90 \%$. Grade 2 organ toxicities were: hypotension with systolic blood pressure $<90 \mathrm{mmHg}$, responding to IV fluids or vasopressors at doses not meeting the criteria for grade 3 and hypoxia requiring supplemental oxygen, and fraction of inspired oxygen $<40 \%$. Grade 3 organ toxicities were: hypotension requiring multiple or high dose vasopressors (as defined by norepinephrine $\geq 20 \mu \mathrm{g} / \mathrm{min}$, dopamine $\geq 10$ $\mu \mathrm{g} / \mathrm{kg} / \mathrm{min}$, phenylephrine $\geq 200 \mu \mathrm{g} / \mathrm{min}$, epinephrine $\geq 10 \mu \mathrm{g} / \mathrm{min}$, vasopressin + norepinephrine $\geq 10$ $\mu \mathrm{g} / \mathrm{min}$, and other vasopressor dose equivalent to norepinephrine $\geq 20 \mu \mathrm{g} / \mathrm{min}$ ), and hypoxia requiring supplemental oxygen $\geq 40 \%$. Grade 4 organ toxicities were: life-threatening hypotension and requirement for ventilator support. Grade 0 was defined as not meeting all conditions above.

\section{Definition of bleeding class}

Bleeding levels are determined according to World Health Organization scales. Patients without bleeding were defined as Grade 0 . Grade 1 included stasis/suppurative/suppurative confined to one or two dependent sites, or sparse/uninflatable, oropharyngeal bleeding with epistaxis lasting $<30 \mathrm{~min}$. Grade 2 included syphilis, hematemesis, hemoptysis, fecal bleeding, blood in stool, musculoskeletal bleeding or soft tissue bleeding not requiring red blood cell transfusion within $24 \mathrm{~h}$ of onset, no hemodynamic instability, extensive epistaxis or oropharyngeal bleeding (i.e., duration $>30 \mathrm{~min}$ ), asymptomatic oral blood blisters, multiple petechiae, $>2 \mathrm{~cm}$ each or any $>10 \mathrm{~cm}$, diffuse or multiple or $>5$ significant purpuric lesions, visible blood in the urine, invasive or abnormal bleeding at the surgical site, unexpected vaginal bleeding within 24 hours, more than two pieces of vaginal bleeding within 24 hours, macroscopically significant intracavitary bleeding, retinal bleeding, with or without visual impairment.Grade 3 includes: trichiasis, hematemesis, hematuria, including intermittent hemorrhage without clots, abnormal vaginal bleeding, bloody stool, epistaxis and oropharyngeal bleeding, traumatic bleeding, etc. Musculoskeletal hemorrhage or soft tissue hemorrhage requiring red blood cell transfusion within 24 hours of onset and without hemodynamic instability, significant intracorporeal hemorrhage visible, cerebral hemorrhage observed on computed tomography, and no neurologic symptoms.Grade 4 includes debilitating hemorrhage, including retinal hemorrhage and visual impairment (defined as visual impairment; patients with suspected visual impairment require ophthalmologist consultation), nonfatal cerebral hemorrhage 
with neurologic signs and symptoms, hemorrhage associated with hemodynamic instability (hypotension, systolic or diastolic blood pressure changes $>30 \mathrm{mmHg}$ ), and fatal hemorrhage of any origin. Bleeding levels 0 to 2 were classified as low bleeding levels, while levels 3 and 4 were classified as high bleeding levels [18].

\section{Assays for plasma cytokines}

Peripheral blood specimens from patients treated with CAR T cells were collected and all specimens were treated with EDTA as an anticoagulant. The peripheral blood specimens were then centrifuged at $800 \times \mathrm{g}$ for $10 \mathrm{~min}$ at room temperature to collect plasma. Plasma levels of IL-2, IL-4, IL-6, IL-10, IL-17A, TNF-a and IFN- $y$ were determined by flow cytometry using the corresponding antibodies (BD Biosciences, Franklin Lakes, NJ, USA) according to manufacturer's instructions. Details of this antibody are given in the supplementary material. Flow cytometry was performed using the BD FACSCalibur system (BD Biosciences).

\section{Statistical analysis}

Sample size assessment was performed using NCSS-PASS software (https://www.ncss.com/software/pass/) version 11.0. Power was set as 0.90 and alpha was 0.5 . Mortality rates $(0.40$ and 0.029$)$ for the severe and non-severe bleeding groups from previous data were entered into PASS. the actual hazard ratio was set to 10. sample size was then calculated using PASS and the minimum sample size was found to be 233 (control group = 203 and experimental group $=30$ ). Our sample size of 400 (363 in the control group and 37 in the experimental group) is more appropriate. The sample size assessment report (Supplementary Material Part II) was also presented. Missing data were estimated and a random forest algorithm using the mouse package in RStudio ( $R$ version 3.6.1). Continuous variables with skewed and normal distributions are expressed as median to interval mean and mean \pm standard deviation. The Mann-Whitney $U$ test and unpaired $t$ test were used for intergroup comparisons. Categorical variables were expressed as percentages and compared using the $\mathrm{K}^{2}$ test. Cumulative mortality was shown using Kaplan-Meier curves and analyzed using the log-rank test. Univariate and multivariate survival analyses for total survival (OS) were assessed using Cox regression models. The significance of covariates on prognosis was visually analyzed using forest plots. Restricted stereo spline analysis was performed using Harrell's Regression Modelling Strategies (rms) package.

To build a bleeding risk model, Lasso regression was used to identify factors associated with bleeding. The contribution of each covariate was quantified and presented in the form of a Nomogram plot with 1000 self-directed internal validations. The consistency of the model created was assessed using a calibration assay. The net clinical benefit of the model compared with traditional bleeding scores was evaluated using decision curve analysis (DCAs). The coordination of each model was visualized using scatterplots and analyzed using 1000 bootstrapping. The association between bleeding grade and survival endpoint was analyzed using Kaplan-Meier curve and log-rank test. Statistical analyses were 
performed using RStudio ( $\mathrm{R}$ version 3.6.1) with rms, risk regression, ggplot2, PredictABLE and surminer packages.

\section{Results}

A total of 400 patients receiving CAR T-cell therapy were enrolled in the study. The median age was 44 years (26-55 years) and $225(56.0 \%)$ of the male patients enrolled in the group. The overall mortality rate is 6.0 per cent. The diagnosis of these patients was as follows: $215(53.8 \%)$ were ALL, $87(21.8 \%)$ were MM, 61 (15.3\%) were NHL, 13 (3.3\%) were AML, 10 (2.5\%) were mixed acute leukemia, $5(1.3 \%)$ were Hodgkin's disease and 4 (1.0\%) were chronic myeloid leukaemia. Chronic lymphocytic leukemia, herpetic plasma cell dendritic cell tumor, Waldenstrom giant cell leukemia, plasma cell leukemia, and POEMS syndrome were all treated in only 1 patient. Prior to CAR T-cell therapy, $118(30.0 \%)$ patients received hematopoietic stem cell therapy. The highest proportion of patients treated with anti-CD19-directed CAR T-cell therapy (237 [59.0\%]) was seen in all types of CAR T-cell therapy.77 (19.0\%) patients received antiCD19 + B-cell maturation antigen CAR T-cell therapy and 45 (11.0\%) received anti-CD19 + anti-CD22 CAR T-cell therapy. Of all patients, CRS occurred in 292 (73.0\%), with 73 (18.0\%) experiencing severe CRS stages (stage III or IV). A total of 201 (50.0\%) patients received blood transfusions and 237 (59.0\%) patients achieved complete remission after receiving CAR T-cell therapy (Table 1).

Of the total 400 patients, $44(11.0 \%)$ had bleeding events, of which $23(52.2 \%)$ were grade $4,14(31.8 \%)$ were grade $3,2(4.5 \%)$ were grade 2 and $5(11.4 \%)$ were grade 1 . Of these, $22(50.0 \%)$ patients had mixed bleeding, 6 (13.6\%) colon bleeding, 6 (13.6\%) urinary bleeding, 4 (9.1\%) skin bleeding, 3 (6.8\%) respiratory bleeding, 2 (4.5\%) eye bleeding and 1 (2.3\%) oral bleeding. We define grade 3 and 4 bleeding as severe bleeding. Among the 37 patients with severe bleeding, the overall mortality rate was $32.4 \%$ (Table 1 ).

According to univariate analysis, the severe bleeding group was a strong predictor of total mortality (hazard ratio $[\mathrm{HR}]$ 13.04, 95\% confidence interval [Cl] 5.82-29.18; $\mathrm{P}<0.001$ ). The Kaplan-Meier curve showed an increased incidence of cumulative mortality in the severe bleeding group compared with the non-severe bleeding group $(\mathrm{P}<0.001)$ (Fig. 2A). Also, according to the survival curves, DIC patients had higher mortality than non-DIC patients (HR 8.11, 95\% Cl 3.17-20.71; $\mathrm{p}<0.001$ ) (Fig. 2B). In addition, stage III and IV CRS, hemoglobin $<100 \mathrm{~g} / \mathrm{L}$, platelets $<30 \times 109$, C-reactive protein (CRP, $\mathrm{mg} / \mathrm{L}) \geq 23.325$, $\mathrm{TT}(\mathrm{s}) \geq 16.15, \mathrm{IL}-2(\mathrm{pg} / \mathrm{mL}) \geq 4.875, \mathrm{IL}-6(\mathrm{pg} / \mathrm{mL}) \geq 15.09, \mathrm{IL}-10(\mathrm{pg} / \mathrm{mL}) \geq 5.91$ and IFN-y $(\mathrm{pg} / \mathrm{mL}) \geq$ 9.41 were positively correlated with total mortality (Table S1). When adjusted for age and sex, patients in the severe bleeding group also had a higher cumulative incidence of death compared with patients in the non-severe bleeding group (Table S1). After multivariate adjustment for all variants, it was statistically significant $(P<0.05)$ and the severe bleeding group was associated with a more than 4 -fold increased risk of death (HR 4.73, 95\% Cl 1.45-15.44; $\mathrm{P}<0.01)$ (Table S2).

Severe bleeding as a fatal event after CAR T-cell therapy has shown significant prognostic value for multiple outcomes. Successful prediction may help prevent bleeding and suggests an improved prognosis after CAR T-cell therapy. Therefore, we modeled the association of multivariate risk scores with 
severe bleeding. Univariate analysis showed that stage III and IV CRS, hemoglobin $<100 \mathrm{~g} / \mathrm{L}$, platelets < $30 \times 109$, APTT(s) $\geq 31.4, \mathrm{PT}(\mathrm{s}) \geq 12.2, \mathrm{CRP}(\mathrm{mg} / \mathrm{L}) \geq 23.325, \mathrm{IL}-2(\mathrm{pg} / \mathrm{mL}) \geq 4.875, \mathrm{IL}-4(\mathrm{pg} / \mathrm{mL}) \geq 2.42$, $\mathrm{IL}-6(\mathrm{pg} / \mathrm{mL}) \geq 15.09, \mathrm{IL}-10(\mathrm{pg} / \mathrm{mL}) \geq 5.91, \mathrm{TNF}-\mathrm{a}(\mathrm{pg} / \mathrm{mL}) \geq 2.12$ were risk factors for severe bleeding (Table 3). When adjusting for model-1 (age and sex) and model-2 (age, sex, HSCT, IL-6 knockout, BLAST percentage, CAR-T type, diagnosis, CAR-T cell count and complete remission), TNF-a and CRS stages were also risk factors for CAR-T treatment-related bleeding (Table 2). Multivariate regression was statistically significant $(P<0.05)$ for all variants, showing that stage III and IV CRS $(O R 6.07,95 \% \mathrm{Cl} 2.35-$ 16.76; $\mathrm{P}<0.001)$ and high TNF-a levels (OR 4.00, 95\% Cl 1.53-11.35; $\mathrm{P}<0.001$ ) were independent factors of bleeding in patients after CAR T treatment (Table 3). Without assuming a linear relationship, a Logistic regression model was constructed using restrictive cubic splines to determine whether TNF-a levels affect the risk of severe bleeding and to show age- and sex-adjusted OR for severe bleeding, and TNF-a levels were found to be linearly correlated with increased risk over the entire range of TNF-a level values (Fig. 3). Next, we selected CRS stage, transfusion volume, platelet percentage, platelet count, PT, IL-6, and TNF-a levels to build predictive models by multivariate Lasso regression and Logistic regression (Figures S1A, 1B). To quantify the contribution of each covariate to the severe bleeding grade, a logistic model of the nomogram was generated, as shown in Fig. 4A. The novel bleeding scores derived from this model showed good correction (C-statistic $=0.905)(F i g .4 B)$, and the model conveyed a greater clinical benefit compared to established bleeding scores such as MOBRI (Figure S2A) and HAS-BLED (19). In addition, clinical impact curves for patients with hematologic malignancies after CAR T-cell therapy also showed higher accuracy of our new bleeding model compared to the HAS-BLED and MOBRI models (Figure S3AC).

\section{External validation of nomogram for Car-T associated bleeding}

Nomogram was externally validated by the calibration plots in Fig. 5 and by calculating bootstrap C statistics in an independent validation cohort of 39 patients. In the external validation step, Nomogram predicted a $\mathrm{C}$ index of 0.700 for Car-T-related bleeding (Fig. 5A), indicating that the model is well discriminated. The calibration curve shows that the nomogram was well calibrated; the 5 -year OS shows optimal agreement between the actual observations and the nomogram predicted values (Fig. 5B).

\section{Discussion}

This real-world study demonstrates the prognostic value of hemostatic disorders in patients treated with CAR T cells. A total of $11.0 \%$ of patients developed bleeding events after receiving CAR T-cell therapy. Severe bleeding levels were associated with a significant increase in overall mortality. In addition, severe bleeding grade was independently associated with adverse outcomes and had significant authority in identifying high-risk patients. A multivariate bleeding risk model, including CRS stage, transfusion, 
platelet percentage, platelet count, PT, IL-6 and TNF-a levels, successfully predicted the risk of severe bleeding in patients receiving CAR T-cell therapy.

Bleeding events are associated with poorer prognosis in patients treated with CAR T cells. Despite preliminary findings from cross-sectional studies and case reports, only a few studies have suggested a prognostic role for bleeding in patients with hematologic malignancies after CAR T-cell therapy. Maude et al[9] conducted a phase 2, 25-center, single cohort global study in 75 young adult and pediatric patients with CD19 + relapse or refractory B-cell ALL. In their study, patients were found to develop cerebral hemorrhage during CAR T-cell therapy and this hemorrhagic event resulted in death.Turtle et al[19] Another clinical trial of CD19 CAR T-cell therapy applied to 32 adult patients with relapsed and/or refractory B-cell NHL showed that 2 patients died of pelvic and gastrointestinal hemorrhage, respectively.Locke et al[20] showed that 1 out of 7 patients treated with CAR T-cells died of intracranial hemorrhage in the multicenter ZUMA-1 phase 1 study.

Our study included a large sample size and recruited only Chinese, which is an advantage because the findings can be applied to a specific ethnic group. Interestingly, the results of the Cox regression model showed that patients with severe bleeding had a poorer prognosis compared to those without this complication. Even though bleeding is not the direct cause of death in some patients, its malignant role in overall mortality clearly leads to a poor clinical prognosis. Considering the incidence and mortality of severe bleeding events in patients receiving CAR T-cell therapy, effective control of hemostatic disorders may be a critical step in improving prognosis. Although prophylactic infusion of platelets and supplemental clotting factors can improve bleeding risk, a subset of patients with severe bleeding are somewhat resistant to conventional therapy and are prone to an increased risk of death[21]. Thus, identifying risk factors for bleeding, in addition to thrombocytopenia and coagulation dysfunction, may shed new light on bleeding care and improved prognosis after CAR T cell therapy.

We used the machine learning method Lasso regression to screen for factors associated with severe bleeding, using a machine learning approach to control for collisionality[22], multivariate logistic regression of 400 patients showed that CRS and high TNF-a concentrations were independent risk factors for severe bleeding in patients with hematologic malignancies after CAR T-cell therapy.CRS is an inflammatory process. Acute inflammation and infection almost always result in hematologic abnormalities, ranging from inconspicuous laboratory changes to severe DIC[7], and it has long been known that inflammation can lead to activation of the coagulation system. Acute inflammation as a response to a serious infection or trauma can lead to systemic activation of the coagulation system and bleeding[23]. Endotoxins are lipopolysaccharide compounds of Gram-negative bacteria that induce sepsis syndrome and DIC[24]. In addition to the direct positive effect of endotoxins on tissue factor (TF) synthesis, synthesis of cytokines IL-1, TNF- $a$, and IL-6 all stimulate TF formation[25]. An in vitro study showed that TF mRNA production was rapidly induced in blood cells after injection of endotoxin into human volunteers[26] and in vivo, whole blood cells produced TF after incubation with endotoxin or IL-1, TNF- $\alpha$ and IL-6. in vitro, cultured human endothelial cells also induced TF after incubation with TNF- $\alpha$ and IL-1, but their role in DIC remains unknown. To date, the only direct evidence of endothelial cell 
involvement in TF generation is the presence of TF-expressing circulating endothelial cells in patients with sickle cell disease (a possible DIC-related disease)[27]. Studies in primates have revealed the molecular mechanisms of endotoxin-induced coagulation activation[28]. Rapid production and release of proinflammatory cytokines was observed following an intravenous endotoxin challenge.

TNF-a[29] and IL-6[30] are important factors in inducing fibrinolysis and procoagulant changes in the blood. Our study highlights the role of CRS and proinflammatory cytokines during CAR T-cell therapy, and our cohort was significantly different from other studies on bleeding risk factors. Notably, our study not only incorporated a larger sample size, but also underwent cross-validation and internal validation using a bootstrap sampling method. In addition, we confirmed the results of Logistic regression using multivariate models and explored the clinical significance using DCA to assess the prognostic value of bleeding scores[31]. Future multicenter studies, including different ethnic groups, larger sample sizes, and various treatment options, are needed to identify additional risk factors associated with post-CAR T-cell therapy bleeding. Targeted control of these factors may provide new insights into the active control of bleeding and provide new information about the survival benefits for these patients.

Bleeding as a fatal event after CAR T-cell therapy requires early prediction and intervention to reduce subsequent adverse events. To the best of our knowledge, no bleeding scores have been proposed for patients receiving CAR T-cell therapy. In contrast, bleeding scores, including MOBRI and HAS-BLED, have been established as a low-cost, convenient tool for cardiovascular care. The predictive role of these scores in CAR T-cell therapy-related bleeding remains unknown, considering the differences between patients receiving CAR T-cell therapy and those with cardiovascular disease. Through internal guidance, we developed a new bleeding score consisting of 7 factors associated with this therapy, which in our study has a superior estimated clinical benefit in predicting bleeding risk compared to other bleeding scores. The new score not only predicts bleeding, but also has a prognostic effect on OS in these patients. Our results highlight the need for a prognostic model for bleeding in patients receiving CAR T-cell therapy.

\section{Conclusions}

In conclusion, our results show that CAR T-cell therapy-related bleeding predicts worse OS in patients. Bleeding grade provides these patients with additional predictive power beyond other factors. A crossvalidated multivariate score showed good agreement between bleeding grade and efficacy in predicting long-term prognosis in patients receiving CAR T-cell therapy.

\section{List Of Abbreviations}

CAR: chimeric antigen receptor

CD19: Anti-cell differentiation 19

NHL: non-Hodgkin lymphoma 
ALL: acute lymphoblastic leukemia

AML: acute myeloid leukemia

MM: multiple myeloma

CRS: cytokine release syndrome

APTT: active partial thrombinogen time

PTT: partial thromboplastin time

PT: prolonged thromboplastin time

DIC: disseminated intravascular coagulation

TNF-a: tumor necrosis factor-a

IL-6: interleukin-6

HSCT: hematopoietic stem cell transplantation

IFN-ץ: interferon gamma

TT: thrombinogen time

MOBRI: modified outpatient bleeding risk index

\section{Declarations}

\section{Ethics approval and consent to participate}

Informed consent was obtained from all patients or their immediate family members. All research programmes are in line with the guidelines of the Ethics Committee of Soochow University and follow the Declaration of Helsinki.

\section{Consent for publication}

Written informed consent for publication was obtained from all participants.

\section{Availability of data and materials}

All the data and materials are available if necessary. 


\section{Competing interests}

The authors declare no competing financial interests.

\section{Funding}

This work was supported by the National Natural Science Foundation of China (Nos. 81873432 and 81670132), grants from the Jiangsu Province of China (Nos. ZDRCA2016047), Jiangsu Provincial Special Program of Social Development (No. SBE2016740635) and the Priority Academic Program Development of Jiangsu Higher Education Institutions.

\section{Authors' contributions}

QJQ designed and performed research studies, analysed the data, and wrote the manuscript. LV and CJ completed research studies and analysed data. WH contributed to the data analysis and manuscript writing. WH, TYQ, CTT, ZM and CCS add to the collection and analysis of clinical data. LYJ, FY, SWH, QHY, FCC, TXW contributed to the data analysis. PTT, MX, RY contributed to external validation. HY and WDP contributed to the research design, data analysis, writing the manuscript, and supervision of the study.

\section{Acknowledgments}

None.

\section{References}

1. Chakraborty R, Sidana S, Shah GL, Scordo M, Hamilton BK, Majhail NS: Patient-Reported Outcomes with Chimeric Antigen Receptor T Cell Therapy: Challenges and Opportunities. Biol Blood Marrow Transplant 2019, 25(5):e155-e162.

2. Kochenderfer JN, Dudley ME, Kassim SH, Somerville RP, Carpenter RO, Stetler-Stevenson M, Yang JC, Phan GQ, Hughes MS, Sherry RM et al: Chemotherapy-refractory diffuse large B-cell lymphoma and indolent B-cell malignancies can be effectively treated with autologous $\mathrm{T}$ cells expressing an antiCD19 chimeric antigen receptor. J Clin Oncol 2015, 33(6):540-549.

3. Maude SL, Frey N, Shaw PA, Aplenc R, Barrett DM, Bunin NJ, Chew A, Gonzalez VE, Zheng Z, Lacey SF et al: Chimeric antigen receptor T cells for sustained remissions in leukemia. N Engl J Med 2014, 371(16):1507-1517.

4. Lee DW, Kochenderfer JN, Stetler-Stevenson M, Cui YK, Delbrook C, Feldman SA, Fry TJ, Orentas R, Sabatino M, Shah NN et al: T cells expressing CD19 chimeric antigen receptors for acute lymphoblastic leukaemia in children and young adults: a phase 1 doseescalation trial. Lancet 2015, 385(9967):517-528. 
5. Frankel AE, Woo JH, Ahn C, Pemmaraju N, Medeiros BC, Carraway HE, Frankfurt O, Forman SJ, Yang $X A$, Konopleva $M$ et al: Activity of SL-401, a targeted therapy directed to interleukin-3 receptor, in blastic plasmacytoid dendritic cell neoplasm patients. Blood 2014, 124(3):385-392.

6. Brudno JN, Maric I, Hartman SD, Rose JJ, Wang M, Lam N, Stetler-Stevenson M, Salem D, Yuan C, Pavletic S et al: T Cells Genetically Modified to Express an Anti-B-Cell Maturation Antigen Chimeric Antigen Receptor Cause Remissions of Poor-Prognosis Relapsed Multiple Myeloma. J Clin Oncol 2018, 36(22):2267-2280.

7. Brudno JN, Kochenderfer JN: Recent advances in CAR T-cell toxicity: Mechanisms, manifestations and management. Blood Rev 2019, 34:45-55.

8. Turtle CJ, Hanafi LA, Berger C, Gooley TA, Cherian S, Hudecek M, Sommermeyer D, Melville K, Pender $B$, Budiarto TM et al: CD19 CAR-T cells of defined CD4+:CD8+ composition in adult B cell ALL patients. J Clin Invest 2016, 126(6):2123-2138.

9. Maude SL, Laetsch TW, Buechner J, Rives S, Boyer M, Bittencourt H, Bader P, Verneris MR, Stefanski HE, Myers GD et al: Tisagenlecleucel in Children and Young Adults with B-Cell Lymphoblastic Leukemia. N Engl J Med 2018, 378(5):439-448.

10. Shimabukuro-Vornhagen A, Godel P, Subklewe M, Stemmler HJ, Schlosser HA, Schlaak M, Kochanek M, Boll B, von Bergwelt-Baildon MS: Cytokine release syndrome. J Immunother Cancer 2018, 6(1):56.

11. Lee DW, Gardner R, Porter DL, Louis CU, Ahmed N, Jensen M, Grupp SA, Mackall CL: Current concepts in the diagnosis and management of cytokine release syndrome. Blood 2014, 124(2):188-195.

12. Ho-Tin-Noe B, Boulaftali Y, Camerer E: Platelets and vascular integrity: how platelets prevent bleeding in inflammation. Blood 2018, 131(3):277-288.

13. Berbic M, Ng CH, Fraser IS: Inflammation and endometrial bleeding. Climacteric 2014, 17 Suppl 2:4753.

14. Levi M, Ten Cate H: Disseminated intravascular coagulation. N Engl J Med 1999, 341(8):586-592.

15. Wheeler AP, Bernard GR: Treating patients with severe sepsis. N Engl J Med 1999, 340(3):207-214.

16. Barker CA, Kim SK, Budhu S, Matsoukas K, Daniyan AF, D'Angelo SP: Cytokine release syndrome after radiation therapy: case report and review of the literature. $J$ Immunother Cancer 2018, 6(1):1.

17. Neelapu SS, Tummala S, Kebriaei P, Wierda W, Gutierrez C, Locke FL, Komanduri KV, Lin Y, Jain N, Daver $\mathrm{N}$ et al: Chimeric antigen receptor T-cell therapy - assessment and management of toxicities. Nat Rev Clin Oncol 2018, 15(1):47-62.

18. Stanworth SJ, Estcourt LJ, Powter G, Kahan BC, Dyer C, Choo L, Bakrania L, Llewelyn C, Littlewood T, Soutar R et al: A no-prophylaxis platelet-transfusion strategy for hematologic cancers. N Engl J Med 2013, 368(19):1771-1780.

19. Turtle CJ, Hanafi LA, Berger C, Hudecek M, Pender B, Robinson E, Hawkins R, Chaney C, Cherian S, Chen $X$ et al: Immunotherapy of non-Hodgkin's lymphoma with a defined ratio of CD8+ and CD4+ CD19-specific chimeric antigen receptor-modified T cells. Sci Trans/ Med 2016, 8(355):355ra116. 
20. Locke FL, Neelapu SS, Bartlett NL, Siddiqi T, Chavez JC, Hosing CM, Ghobadi A, Budde LE, Bot A, Rossi JM et al: Phase 1 Results of ZUMA-1: A Multicenter Study of KTE-C19 Anti-CD19 CAR T Cell Therapy in Refractory Aggressive Lymphoma. Mol Ther 2017, 25(1):285-295.

21. Silliman CC: PLADO and kids: earlier/increased bleeding after HSCT. Blood 2012, 120(4):704-705.

22. Huang YQ, Liang CH, He L, Tian J, Liang CS, Chen X, Ma ZL, Liu ZY: Development and Validation of a Radiomics Nomogram for Preoperative Prediction of Lymph Node Metastasis in Colorectal Cancer. $J$ Clin Oncol 2016, 34(18):2157-2164.

23. Levi $\mathrm{M}$, de Jonge $\mathrm{E}$, van der Poll $\mathrm{T}$, ten Cate $\mathrm{H}$ : Disseminated intravascular coagulation. Thromb Haemost 1999, 82(2):695-705.

24. van Deventer SJ, Buller HR, ten Cate JW, Aarden LA, Hack CE, Sturk A: Experimental endotoxemia in humans: analysis of cytokine release and coagulation, fibrinolytic, and complement pathways. Blood 1990, 76(12):2520-2526.

25. Camerer $E$, Kolsto $A B$, Prydz H: Cell biology of tissue factor, the principal initiator of blood coagulation. Thromb Res 1996, 81(1):1-41.

26. Franco RF, de Jonge E, Dekkers PE, Timmerman JJ, Spek CA, van Deventer SJ, van Deursen P, van Kerkhoff $\mathrm{L}$, van Gemen $\mathrm{B}$, ten Cate $\mathrm{H}$ et al: The in vivo kinetics of tissue factor messenger RNA expression during human endotoxemia: relationship with activation of coagulation. Blood 2000, 96(2):554-559.

27. Solovey A, Gui L, Key NS, Hebbel RP: Tissue factor expression by endothelial cells in sickle cell anemia. J Clin Invest 1998, 101(9):1899-1904.

28. Levi M, ten Cate H, Bauer KA, van der Poll T, Edgington TS, Buller HR, van Deventer SJ, Hack CE, ten Cate JW, Rosenberg RD: Inhibition of endotoxin-induced activation of coagulation and fibrinolysis by pentoxifylline or by a monoclonal anti-tissue factor antibody in chimpanzees. J Clin Invest 1994, 93(1):114-120.

29. Biemond BJ, Friederich PW, Koschinsky ML, Levi M, Sangrar W, Xia J, Buller HR, ten Cate JW: Apolipoprotein(a) attenuates endogenous fibrinolysis in the rabbit jugular vein thrombosis model in vivo. Circulation 1997, 96(5):1612-1615.

30. McClanahan TB, Ignasiak DP, Juneau P, Finkle C, Winocour PD, Gallagher KP: Antithrombotic effects of $\mathrm{BCH} 2763$, a new direct thrombin inhibitor, in a canine model of venous thrombosis. $J$ Thromb Thrombolysis 1999, 7(3):301-306.

31. Zack CJ, Senecal C, Kinar Y, Metzger Y, Bar-Sinai Y, Widmer RJ, Lennon R, Singh M, Bell MR, Lerman A et al: Leveraging Machine Learning Techniques to Forecast Patient Prognosis After Percutaneous Coronary Intervention. JACC Cardiovascular interventions 2019.

\section{Tables}

Due to technical limitations, table 1, Table 2 and table 3 are only available as a download in the Supplemental Files section. 
Figures

\section{Figure 1}

431 patients undergoing CAR-T therapy registered in the database of our hospital

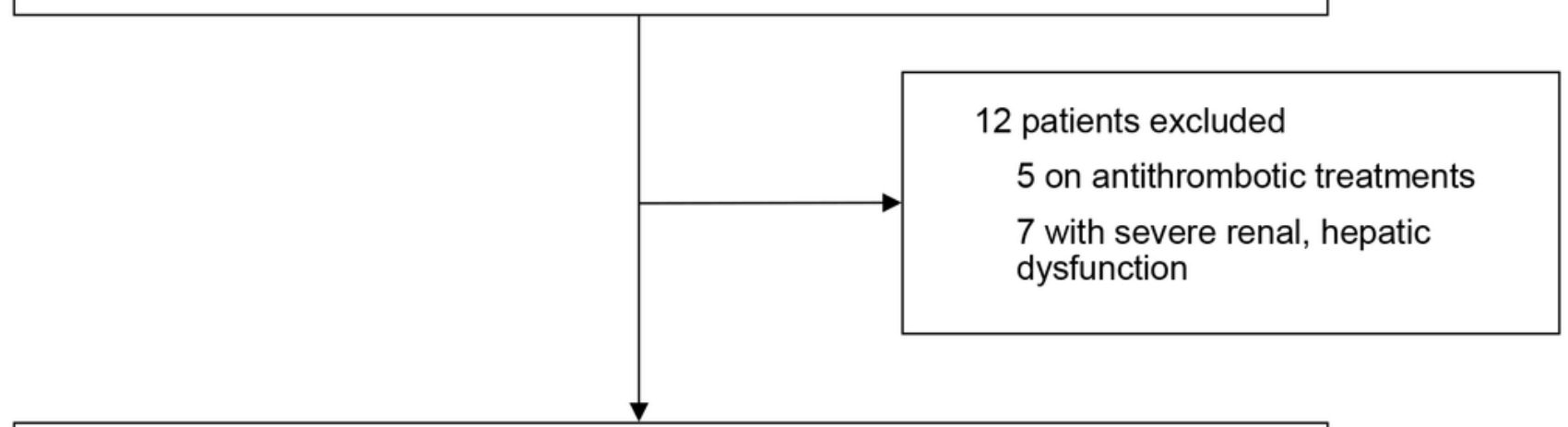

419 patients undergoing CAR-T therapy without antithrombotic treatments

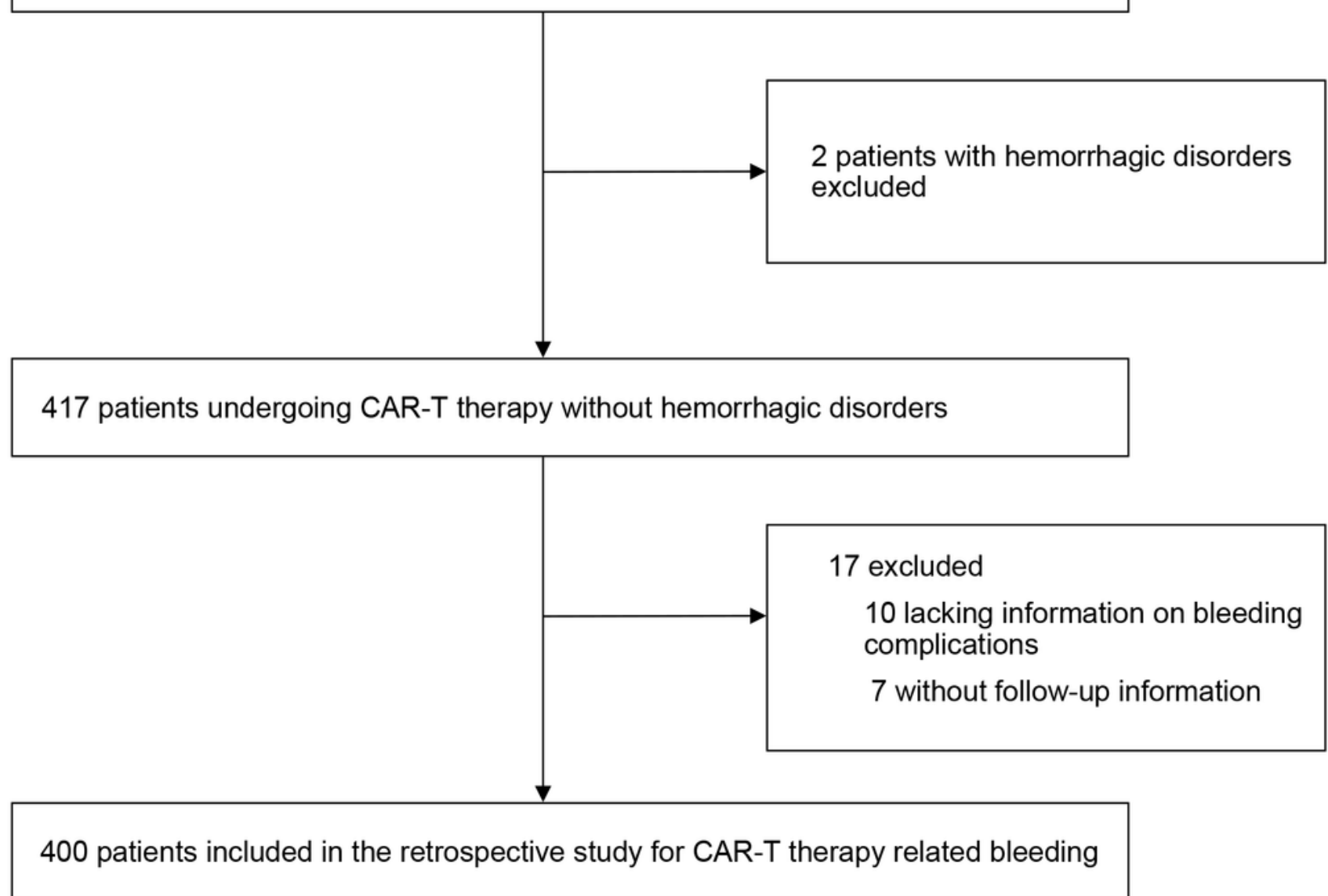

\section{Figure 1}

Flow chart for paitents' selection. 


\section{Figure 1}

431 patients undergoing CAR-T therapy registered in the database of our hospital

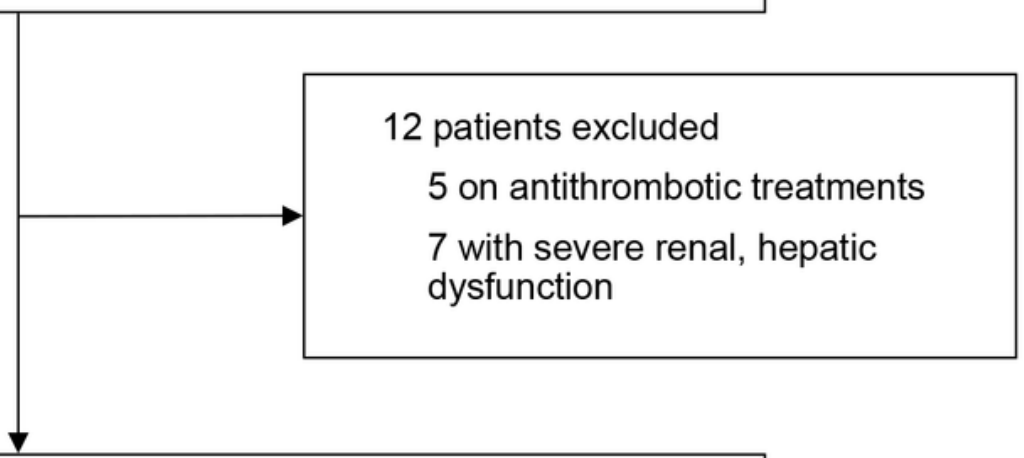

419 patients undergoing CAR-T therapy without antithrombotic treatments

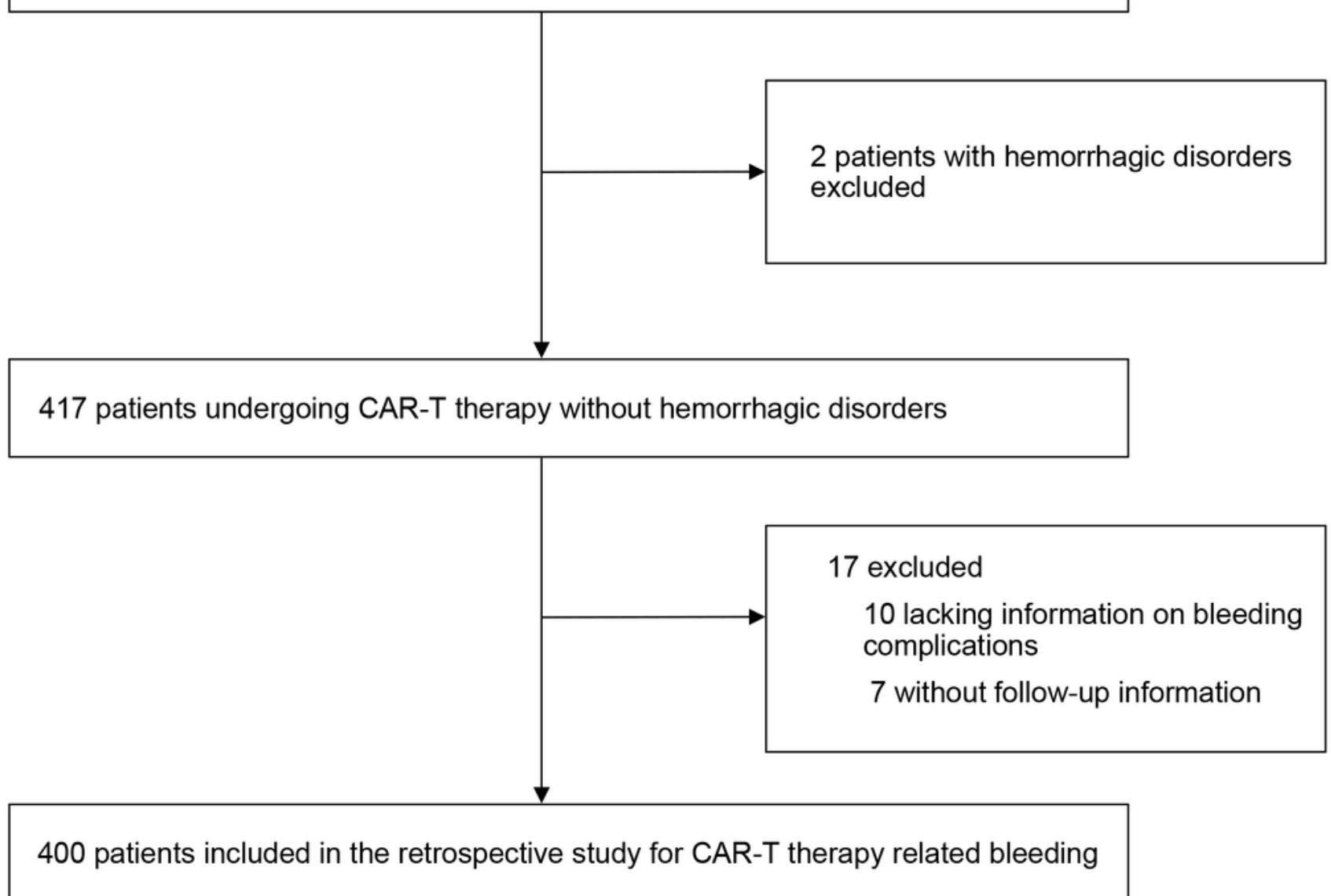

\section{Figure 1}

Flow chart for paitents' selection. 


\section{Figure 1}

431 patients undergoing CAR-T therapy registered in the database of our hospital

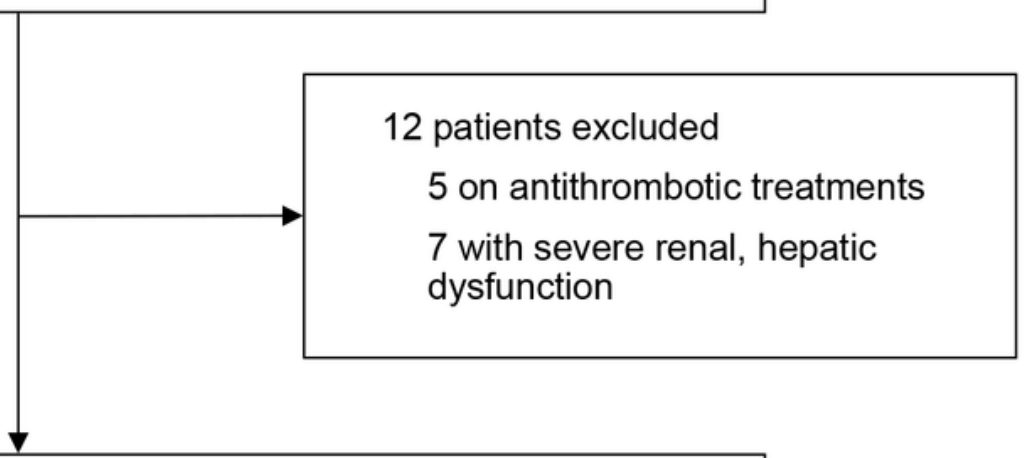

419 patients undergoing CAR-T therapy without antithrombotic treatments

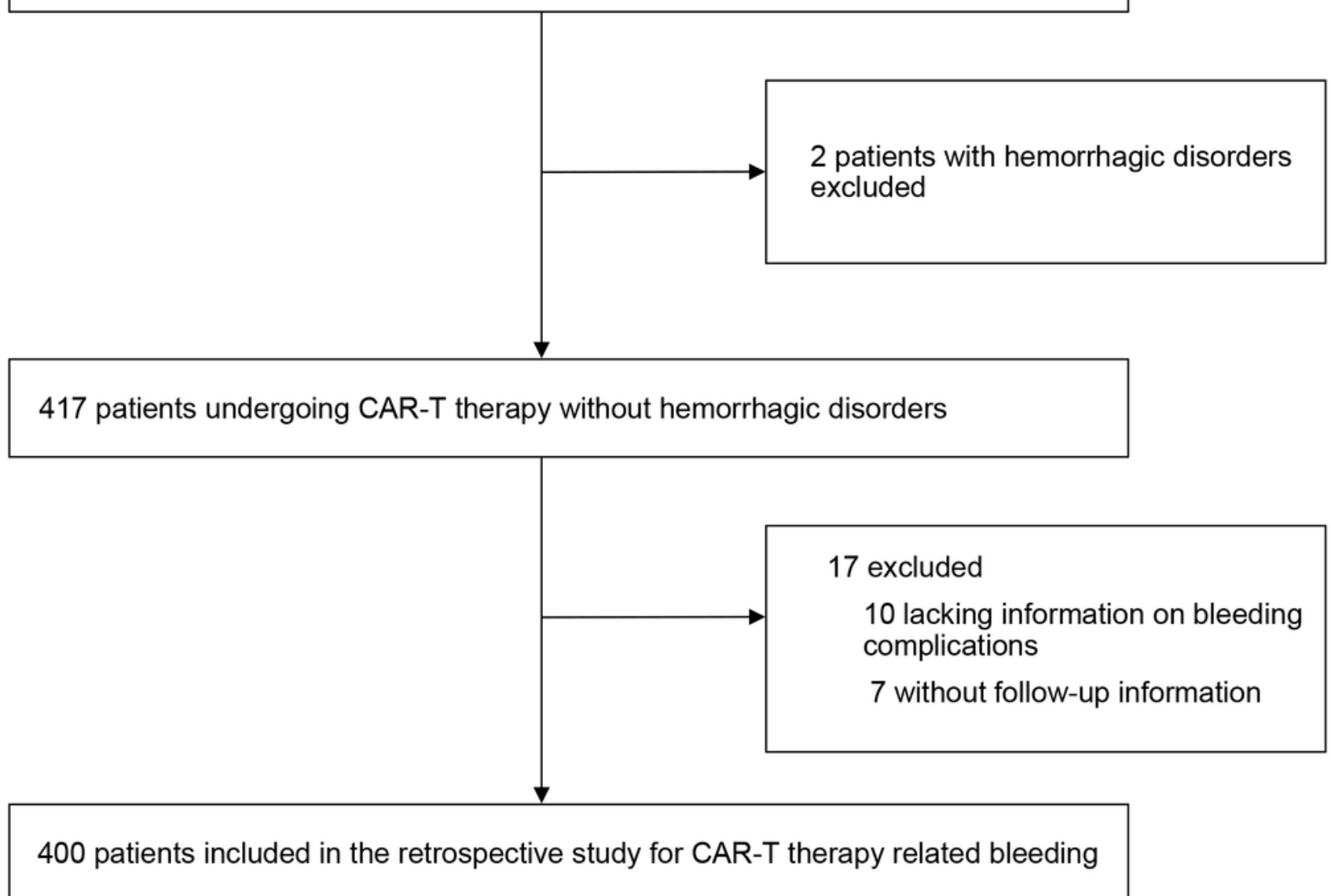

\section{Figure 1}

Flow chart for paitents' selection. 
Figure 2

A
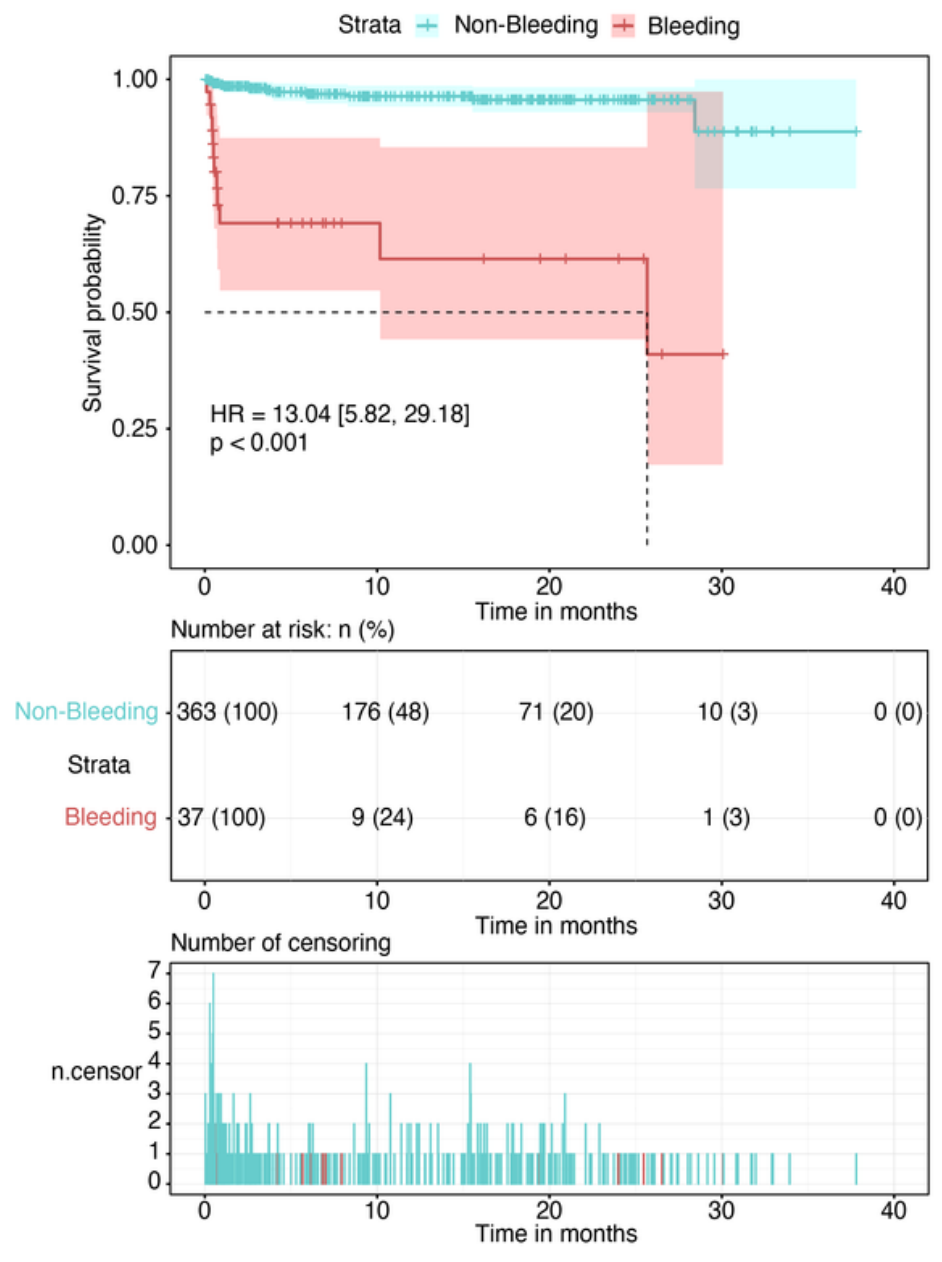

B
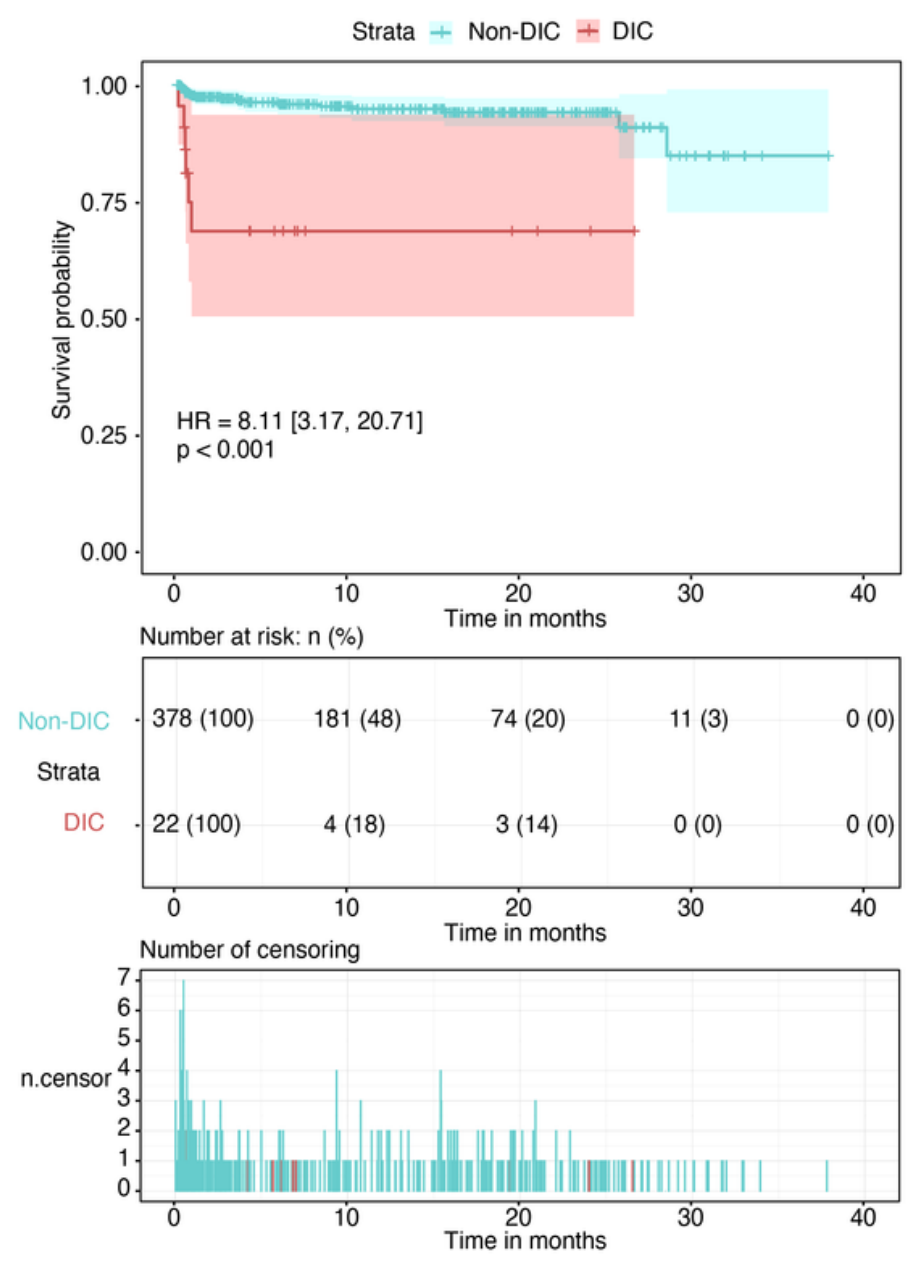

\section{Figure 2}

Kaplan-Meier curves for different groups of patients by bleeding-related variants after CAR T transfusion. A. Kaplan-Meier curves for OS in patients in the non-bleeding and bleeding groups. B. Kaplan-Meier curves for patients with DIC after CAR T transfusion compared with patients without DIC. 
Figure 2

A
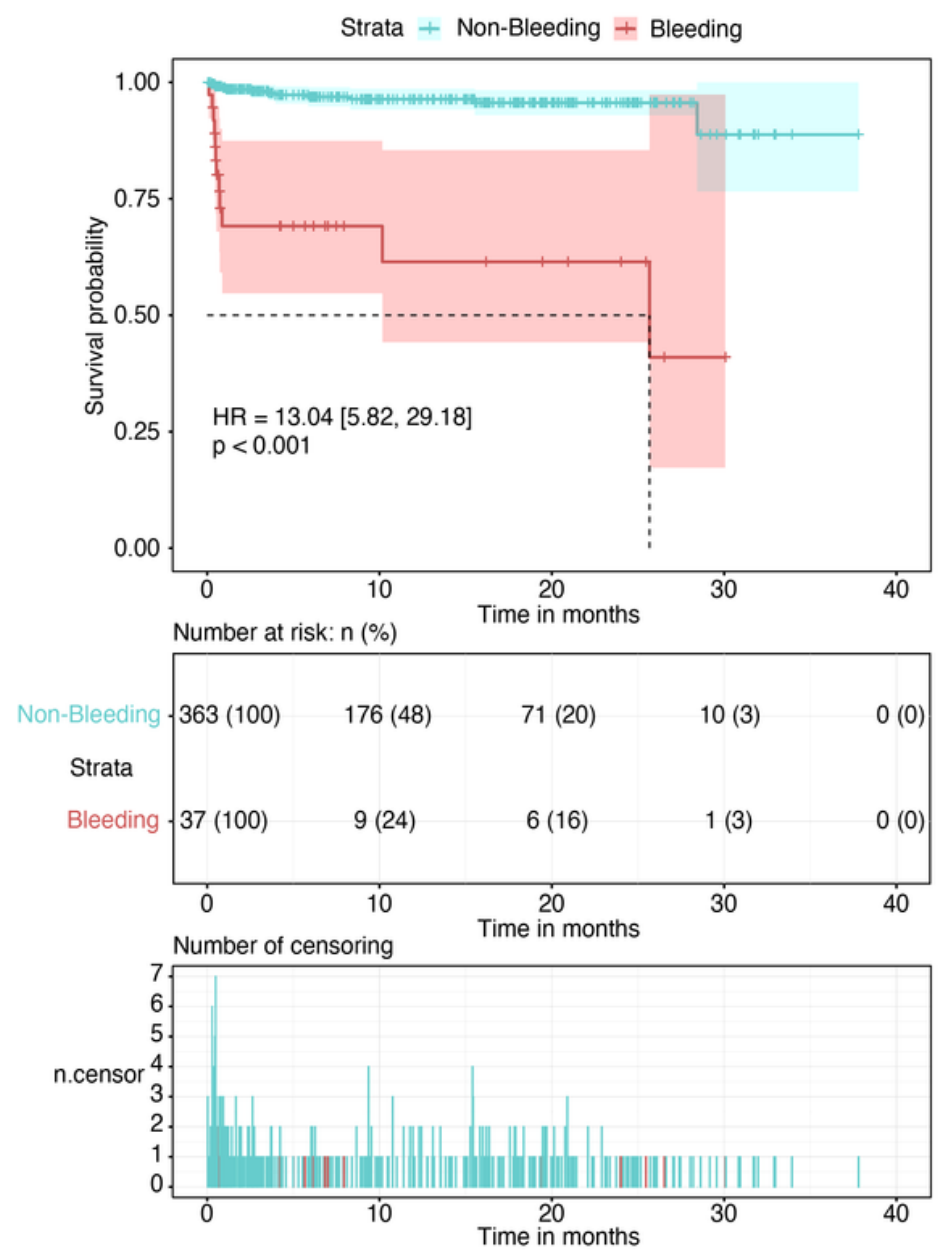

$\mathrm{B}$
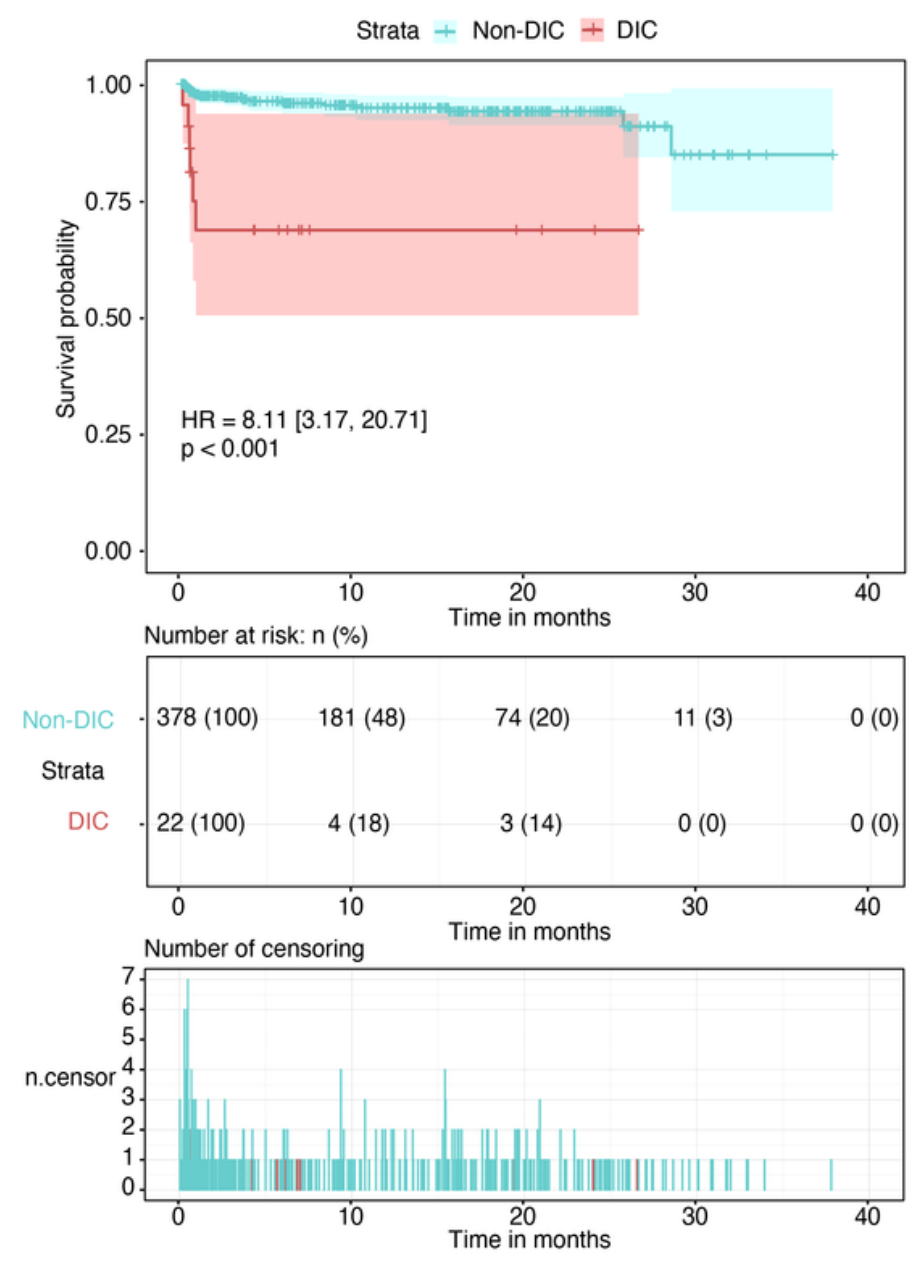

\section{Figure 2}

Kaplan-Meier curves for different groups of patients by bleeding-related variants after CAR T transfusion. A. Kaplan-Meier curves for OS in patients in the non-bleeding and bleeding groups. B. Kaplan-Meier curves for patients with DIC after CAR T transfusion compared with patients without DIC. 
Figure 2

A
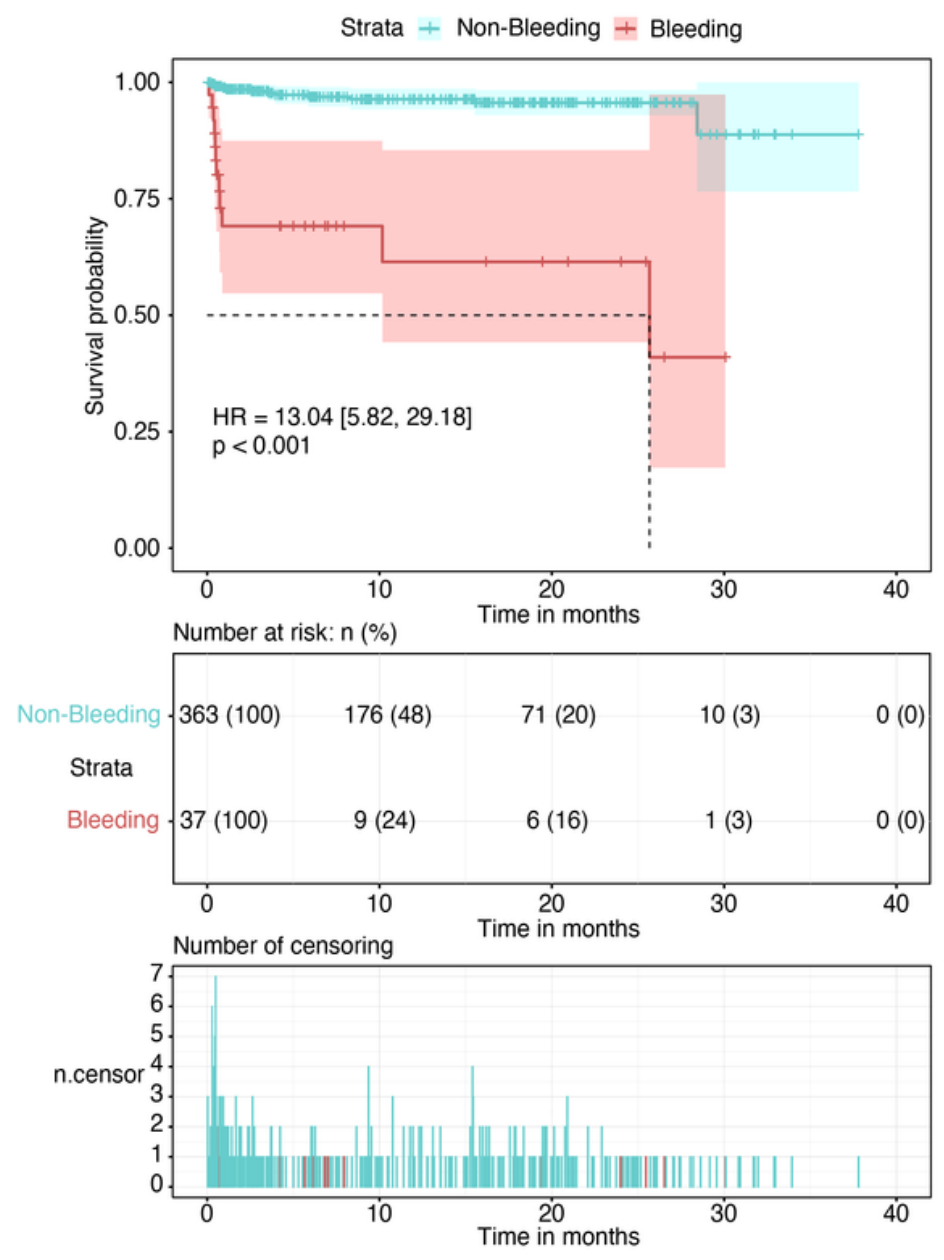

$\mathrm{B}$
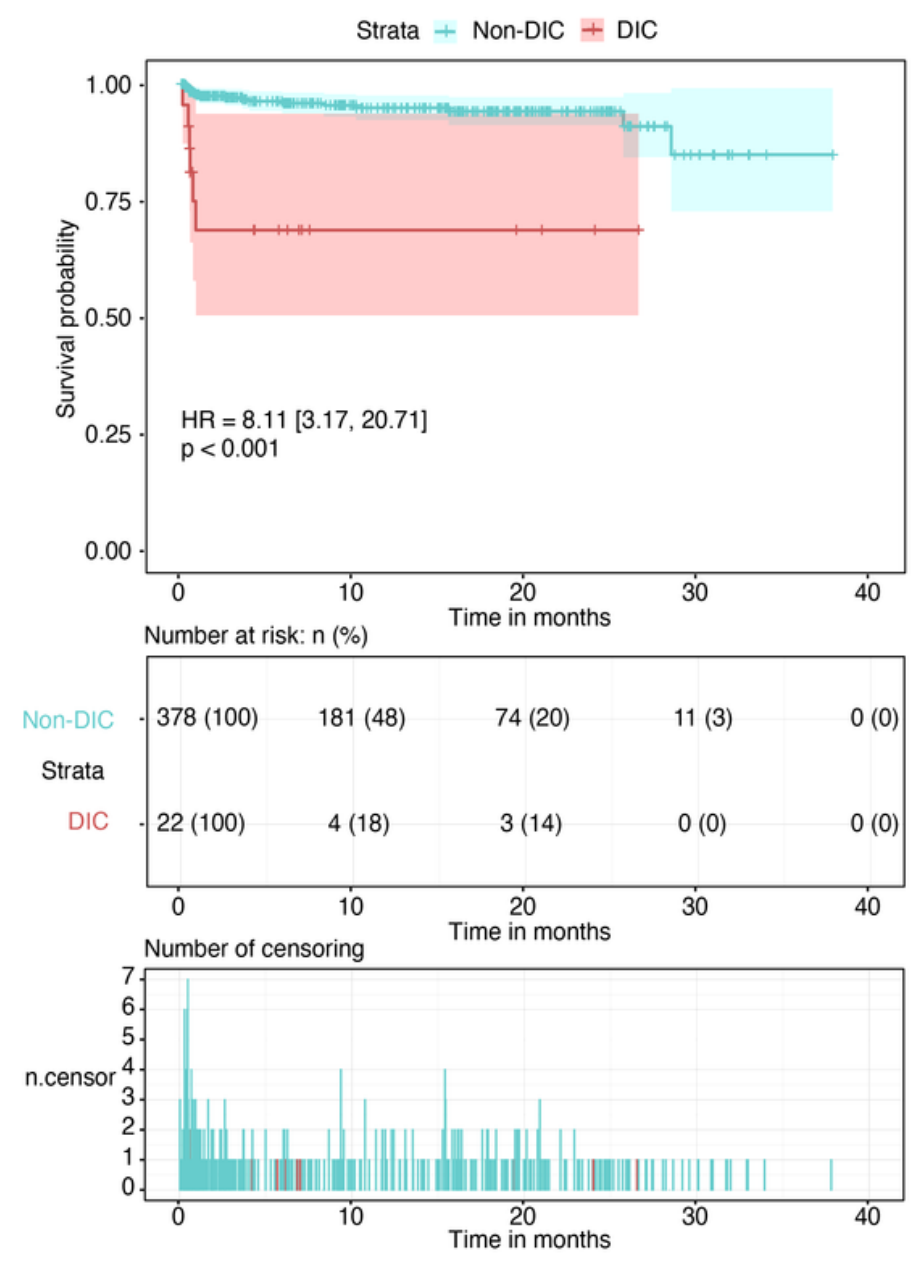

\section{Figure 2}

Kaplan-Meier curves for different groups of patients by bleeding-related variants after CAR T transfusion. A. Kaplan-Meier curves for OS in patients in the non-bleeding and bleeding groups. B. Kaplan-Meier curves for patients with DIC after CAR T transfusion compared with patients without DIC. 


\section{Figure 3}

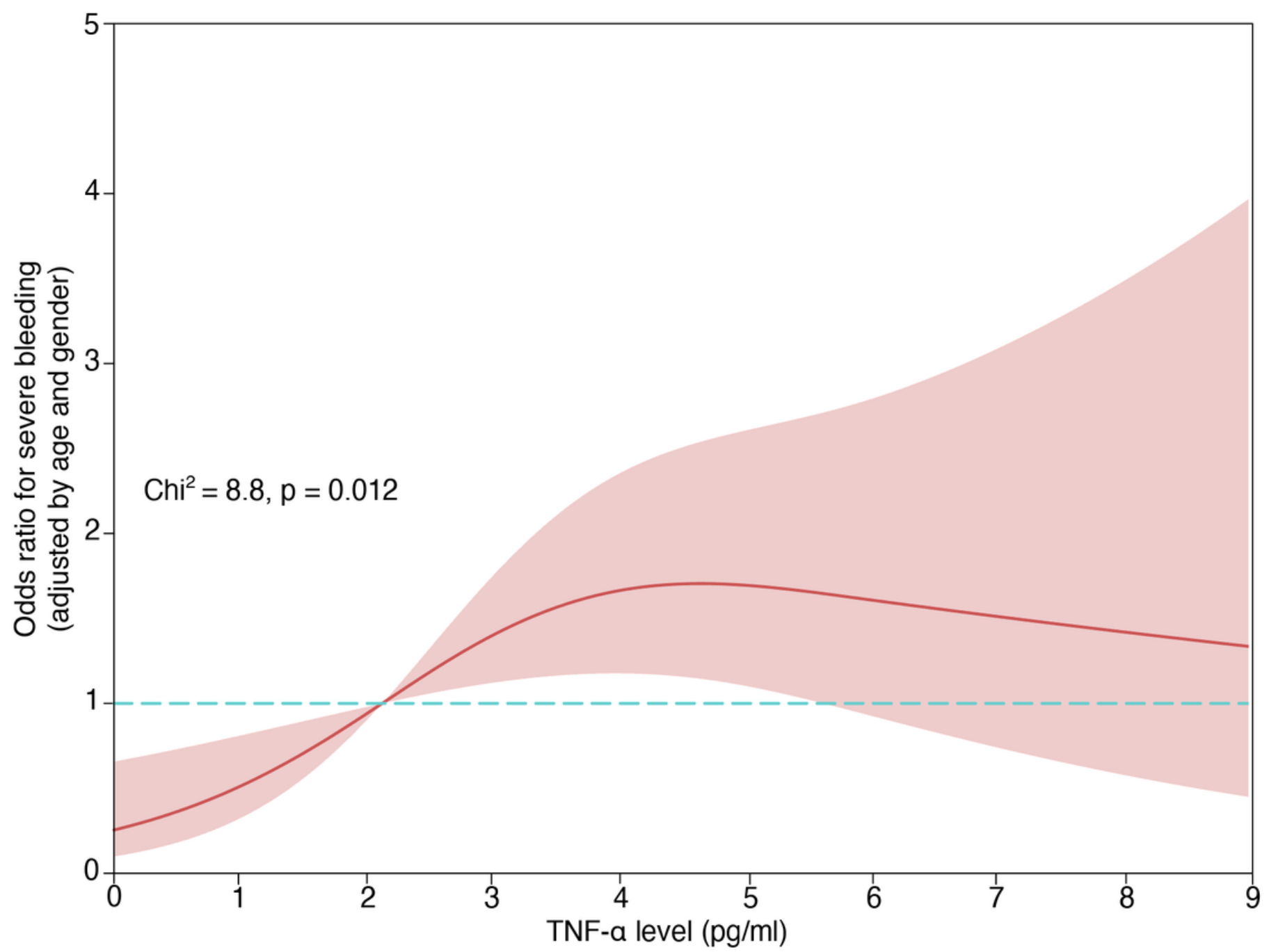

Figure 3

Restricted cubic spline curves for severe bleeding and TNF-a levels. It was estimated using a three-knot model with restricted cubic spline model. Age- and sex-adjusted ORs are shown as solid lines and $95 \%$ Cls are shown as shaded areas. 
Figure 3

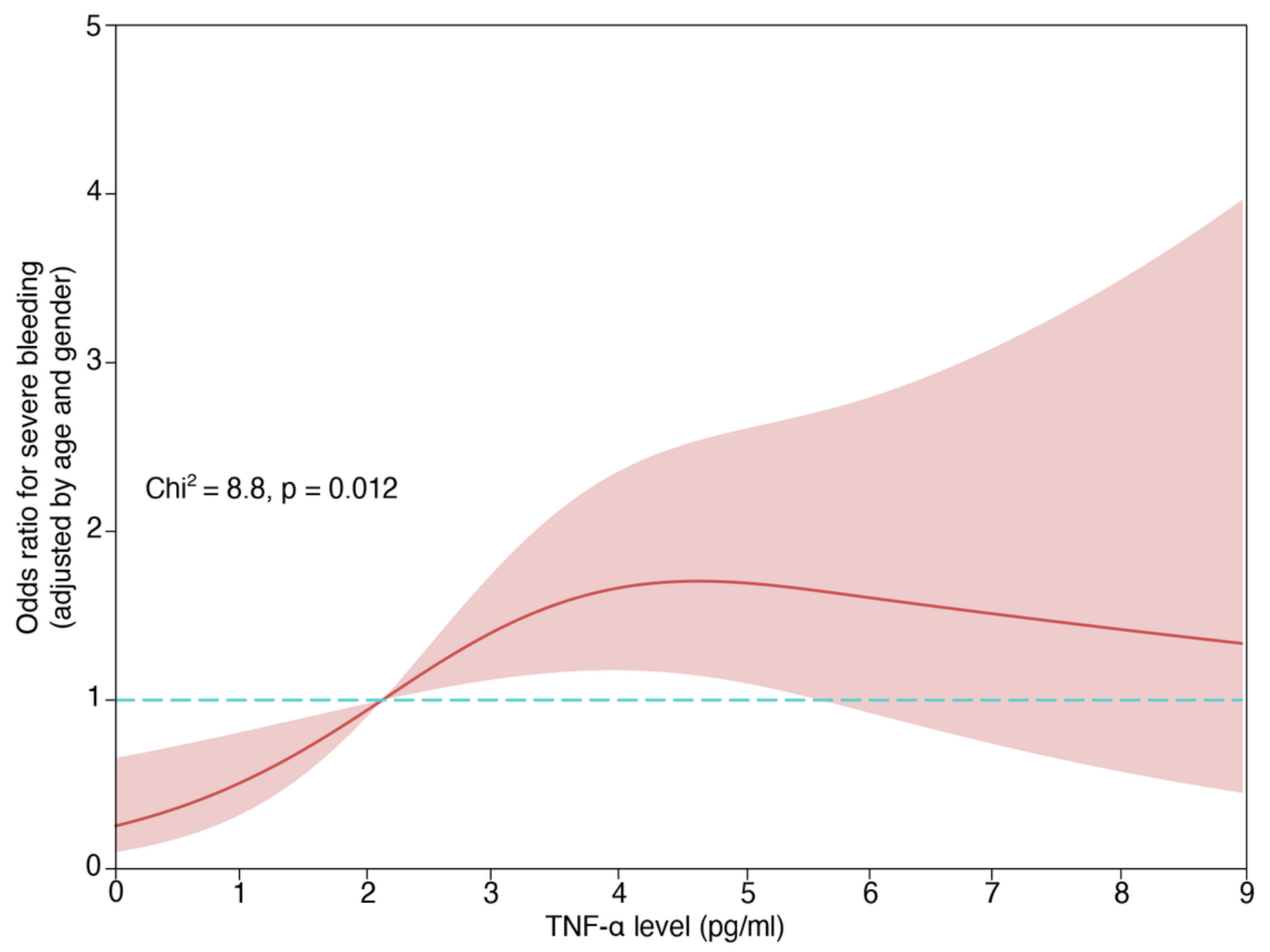

Figure 3

Restricted cubic spline curves for severe bleeding and TNF-a levels. It was estimated using a three-knot model with restricted cubic spline model. Age- and sex-adjusted ORs are shown as solid lines and $95 \%$ Cls are shown as shaded areas. 


\section{Figure 3}

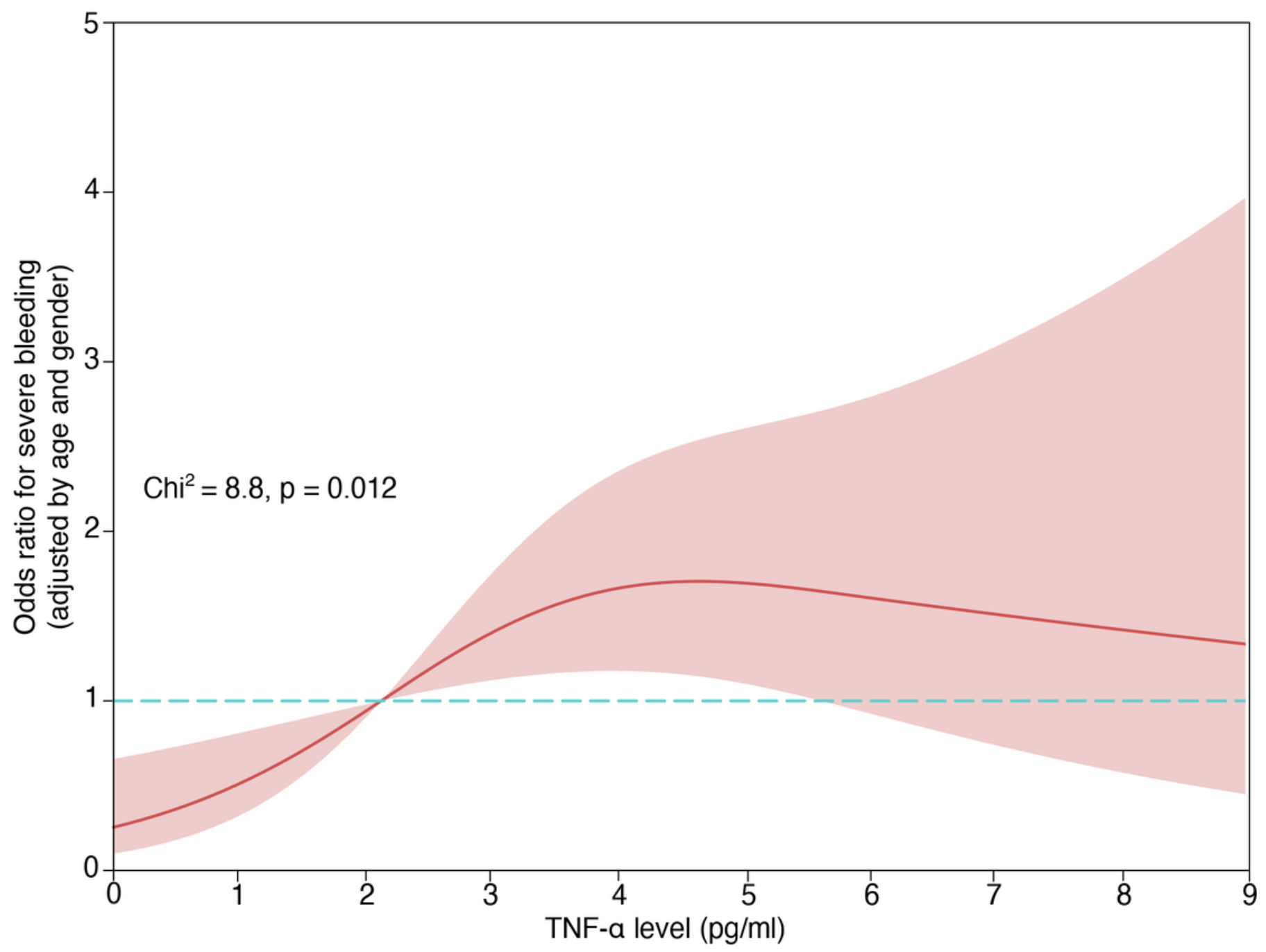

Figure 3

Restricted cubic spline curves for severe bleeding and TNF-a levels. It was estimated using a three-knot model with restricted cubic spline model. Age- and sex-adjusted ORs are shown as solid lines and $95 \%$ Cls are shown as shaded areas. 


\section{Figure 4}

A

Points

CRS Stage

Blood transfusion

Percanteg of blast

Platelet counts $\left(\times 10^{\wedge} 9 / \mathrm{L}\right)$

Prothrombin time (sec)

IL-6 level (pg/mL)

TNF-a level (pg/mL)

Total Points

Car-T associated bleeding occurrence rate

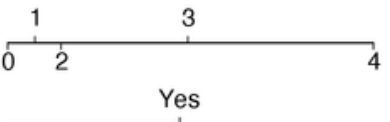

No

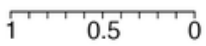

$450^{\prime} 200^{\prime} 0$

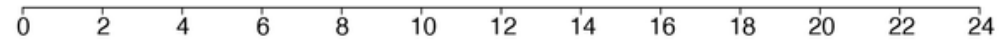

$0 \quad 13000$

\begin{tabular}{llllll}
\hline 0 & 2 & 4 & 6 & 8 & 10121416182022
\end{tabular}

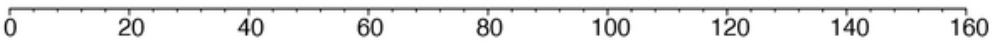

$\begin{array}{llllllllll}0.001 & 0.01 & 0.05 & 0.1 & 0.2 & 0.4 & 0.6 & 0.8 & 0.9 & 0.95\end{array}$

B

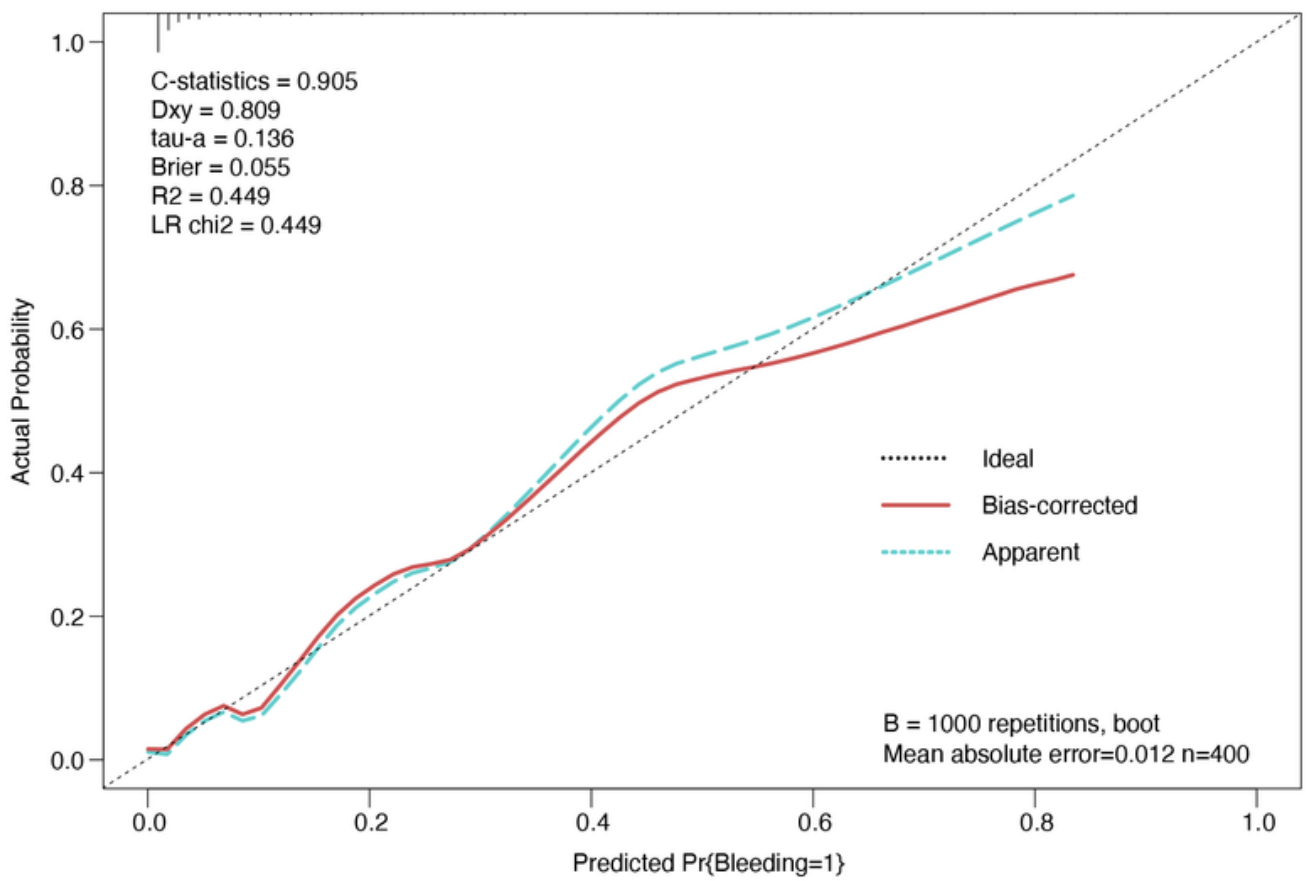

\section{Figure 4}

Nomogram of bleeding estimates in patients with hematologic malignancies after CAR-T transfusion and its predictive performance. A. Nomogram of bleeding risk estimates in patients with hematologic malignancies after CAR-T transfusion with different variants. When using the Nomogram plot, locate the position of each variable on the axis, then draw a line on the integral axis, sum the scores of all variables, draw a line at the lower line of the Nomogram plot, and draw a line on the total integral axis to determine 
position of each variable on the axis, then draw a line on the integral axis, sum the scores of all variables, draw a line at the lower line of the Nomogram plot, and draw a line on the total integral axis to determine the bleeding probability. B.Validity of the Nomogram in estimating the predictive performance of bleeding risk in patients with hematologic malignancies after CAR-T transfusion $(n=400)$.

\section{Figure 4}

\section{A}

Points

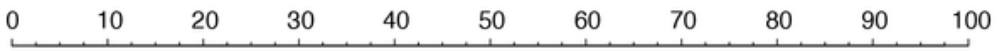

CRS Stage

Blood transfusion

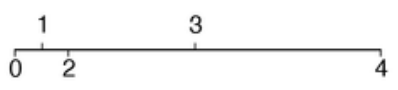

Percanteg of blast
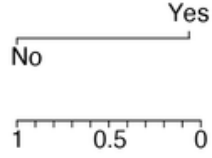

Platelet counts $\left(\times 10^{\wedge} 9 / \mathrm{L}\right)$

$450 ' 200 ' 0$

Prothrombin time (sec)

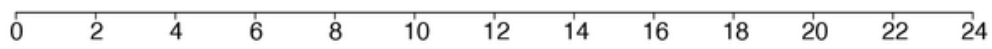

IL-6 level (pg/mL)

$0 \quad 13000$

TNF-a level (pg/mL)

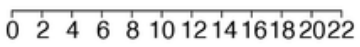

Total Points

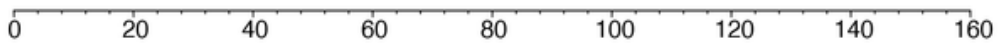

Car-T associated bleeding occurrence rate

$\begin{array}{lllllllllll}0.001 & 0.01 & 0.05 & 0.1 & 0.2 & 0.4 & 0.6 & 0.8 & 0.90 .95\end{array}$

B

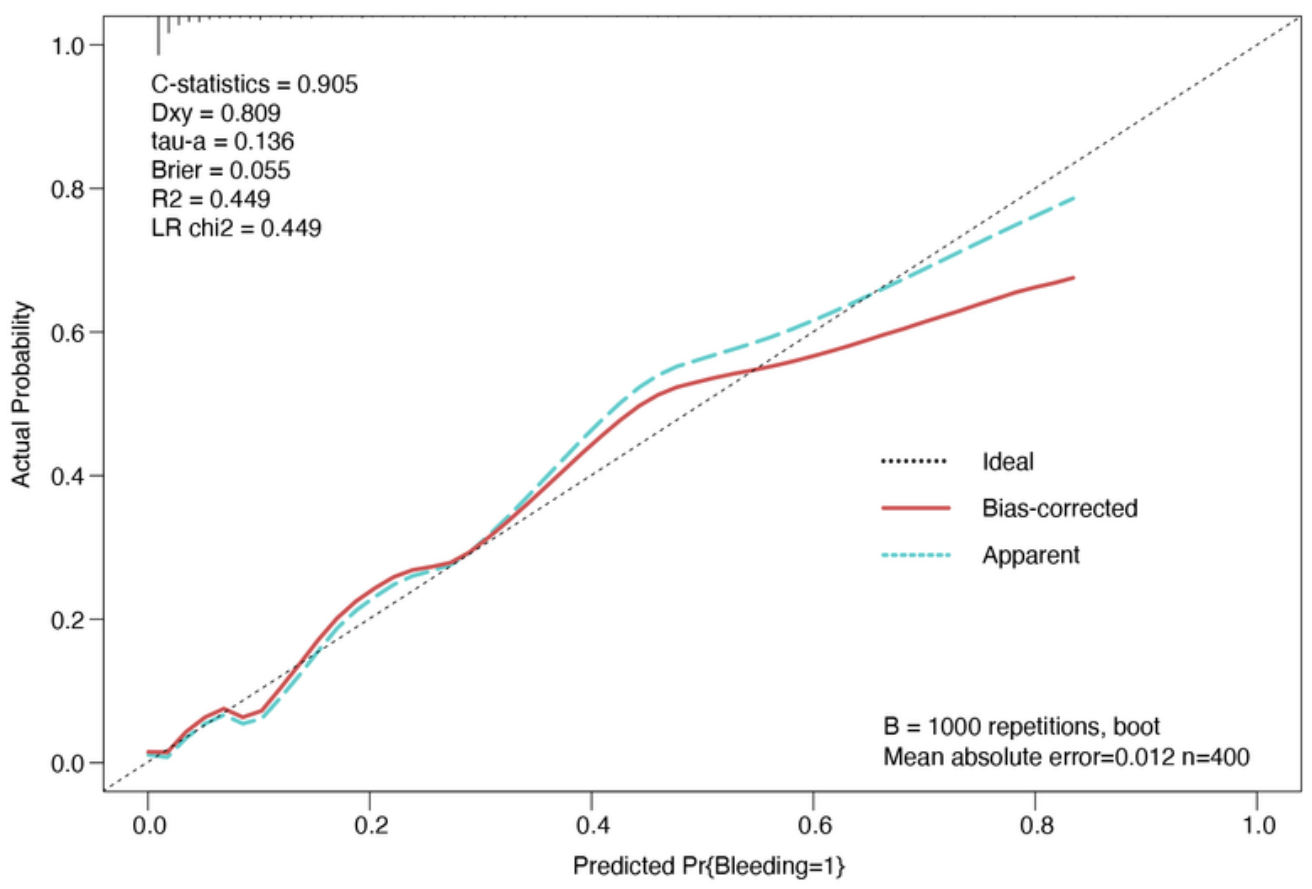

Figure 4 
Nomogram of bleeding estimates in patients with hematologic malignancies after CAR-T transfusion and its predictive performance. A. Nomogram of bleeding risk estimates in patients with hematologic malignancies after CAR-T transfusion with different variants. When using the Nomogram plot, locate the position of each variable on the axis, then draw a line on the integral axis, sum the scores of all variables, draw a line at the lower line of the Nomogram plot, and draw a line on the total integral axis to determine the bleeding probability. B.Validity of the Nomogram in estimating the predictive performance of bleeding risk in patients with hematologic malignancies after CAR-T transfusion $(n=400)$.

\section{Figure 5}

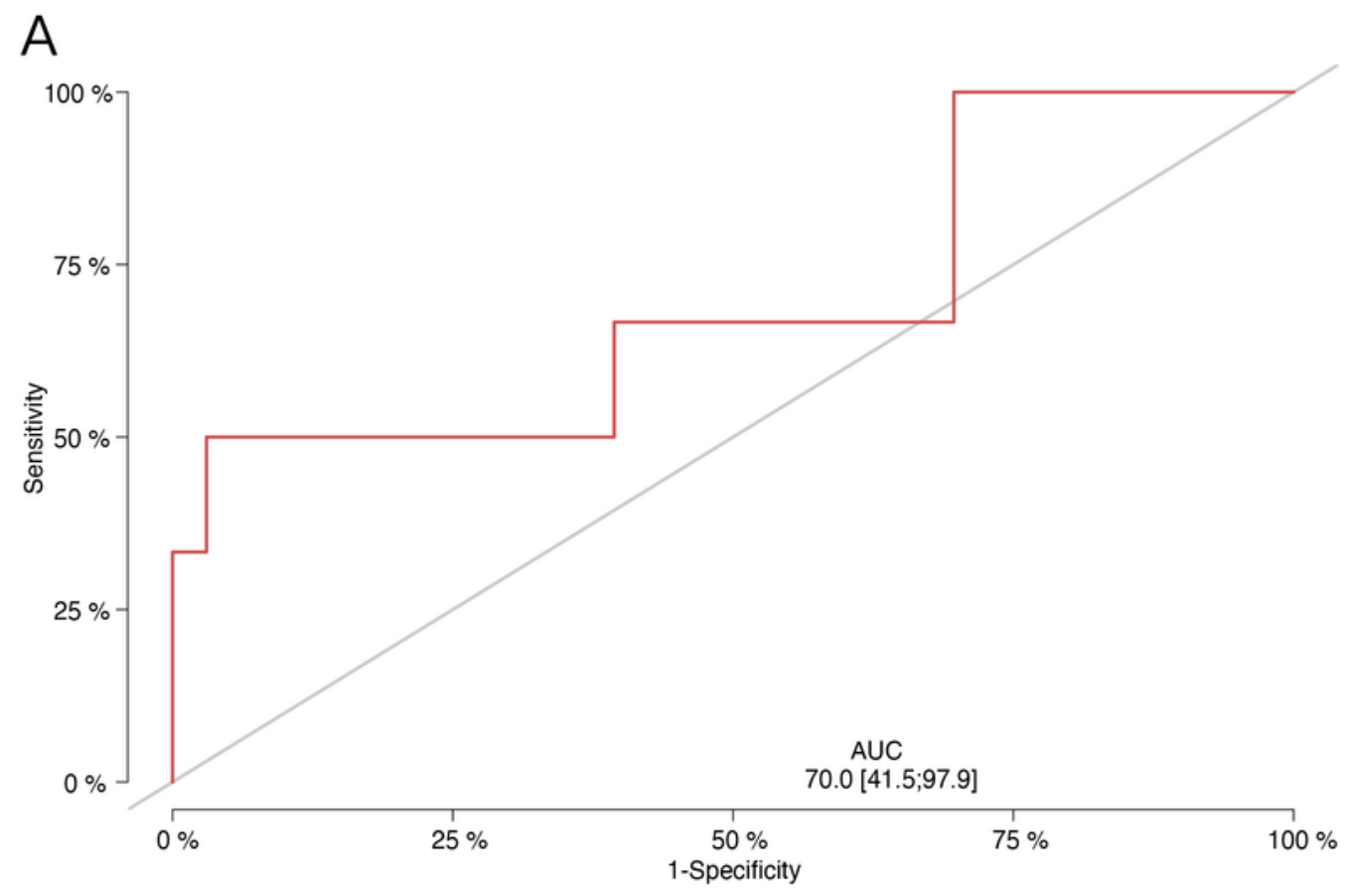

B

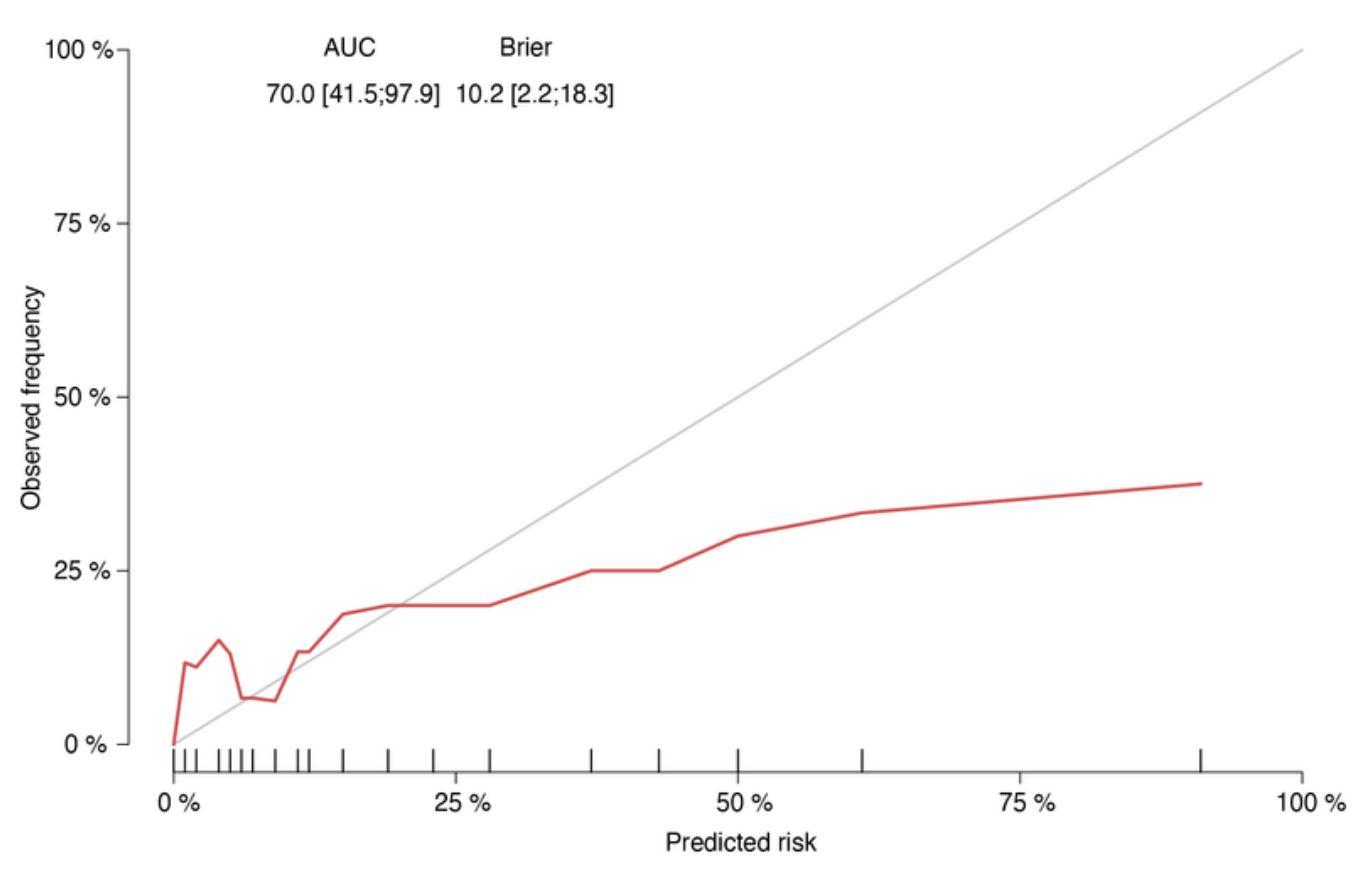




\section{Figure 5}

External validation of the prediction of hematological malignancy bleeding events after CAR-T cell therapy using Nomogram in the validation cohort. A. Discrimination: area under the receiver operating characteristic (ROC) curve (AUC) of 0.72. B. Correction: calibration curve for predicting CAR-T-related bleeding events.

\section{Figure 5}

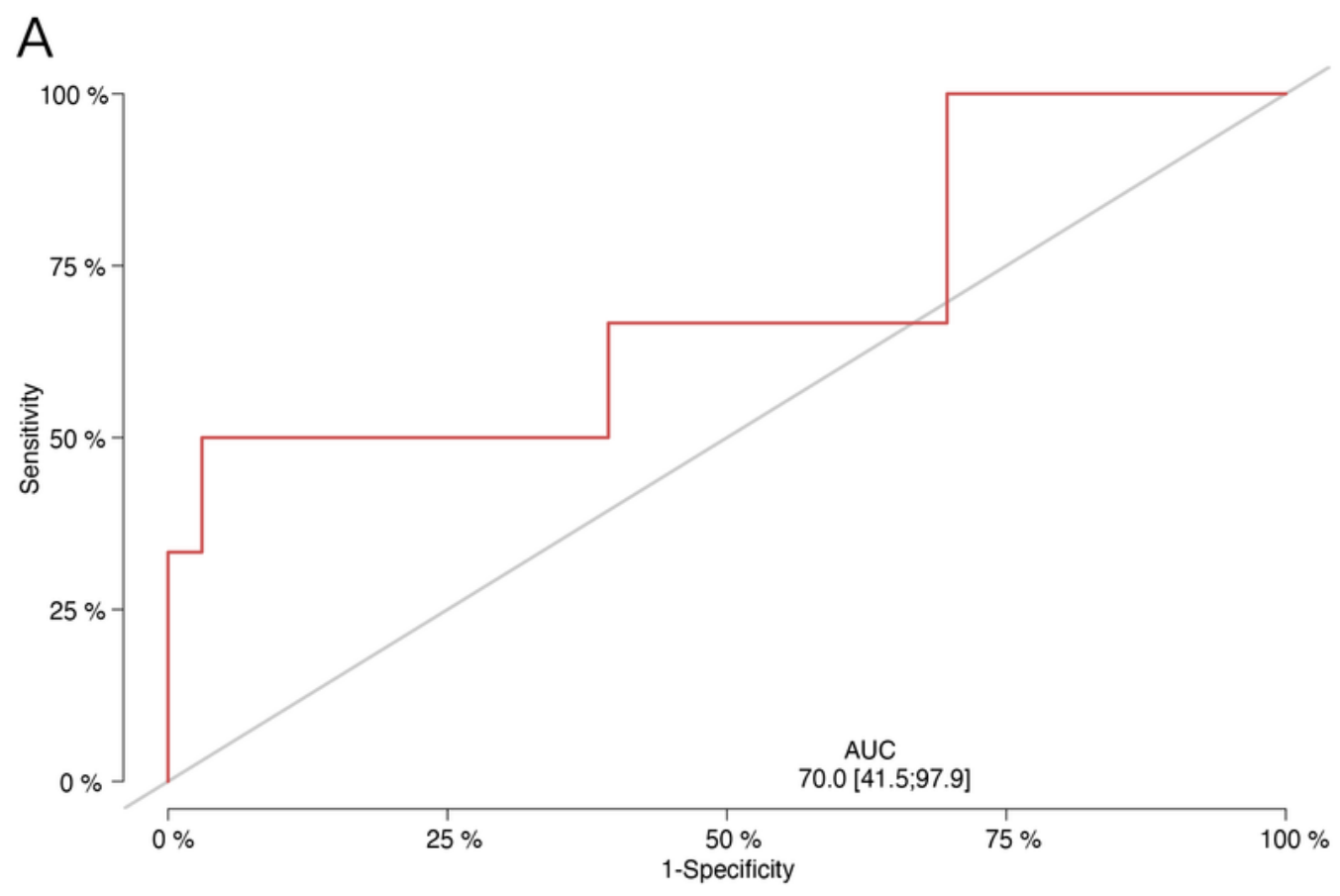

B

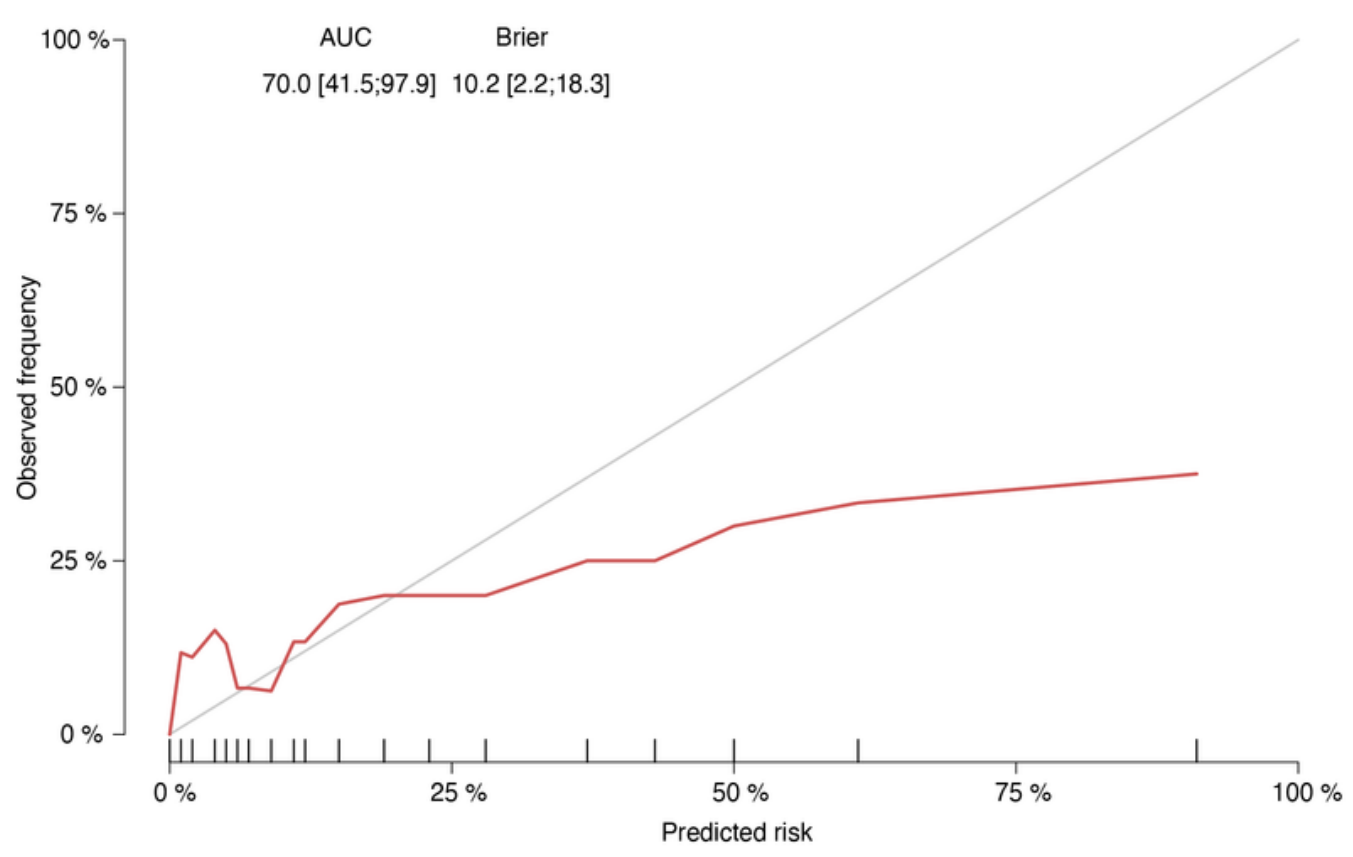

Figure 5 
External validation of the prediction of hematological malignancy bleeding events after CAR-T cell therapy using Nomogram in the validation cohort. A. Discrimination: area under the receiver operating characteristic (ROC) curve (AUC) of 0.72. B. Correction: calibration curve for predicting CAR-T-related bleeding events.

\section{Figure 5}

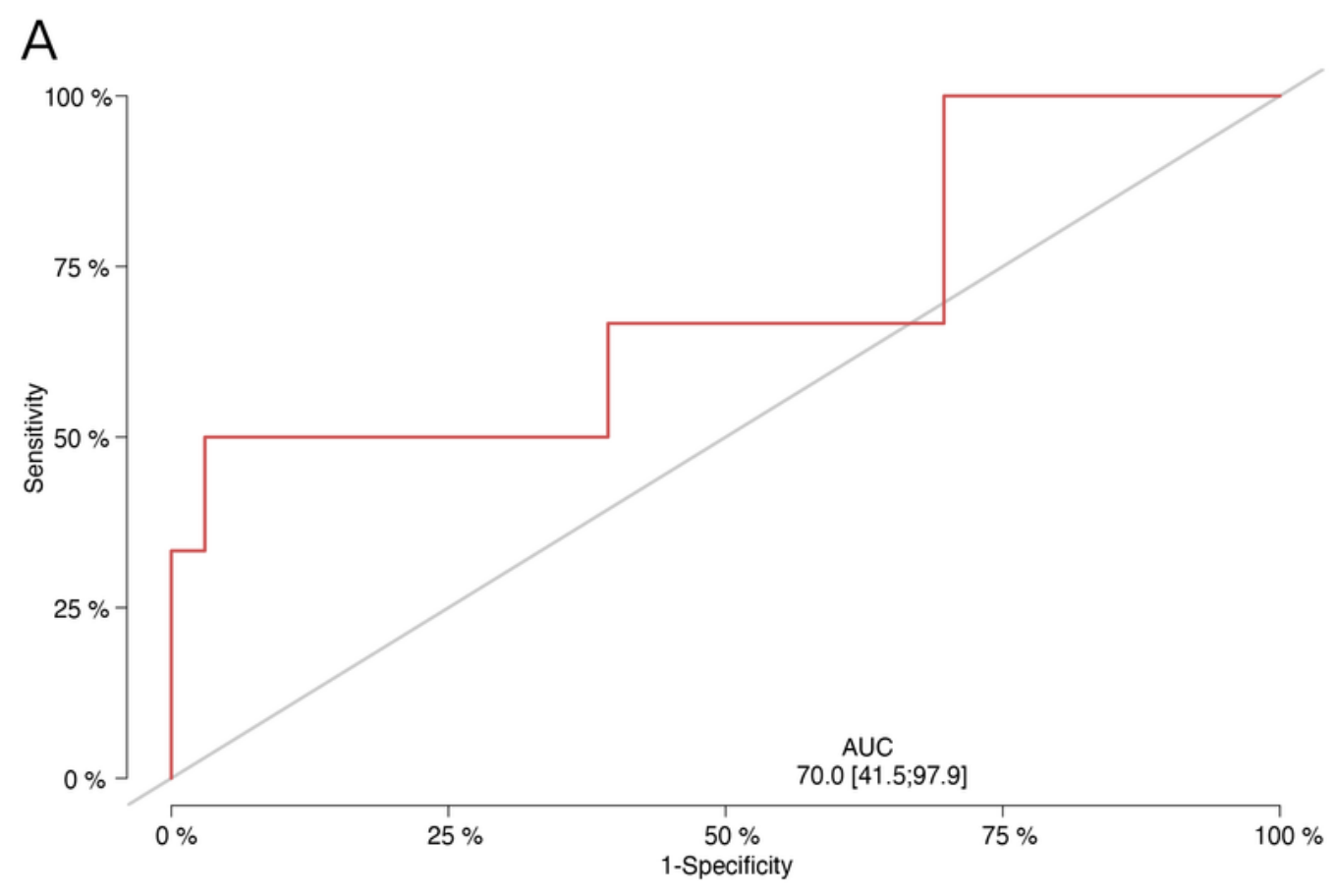

B

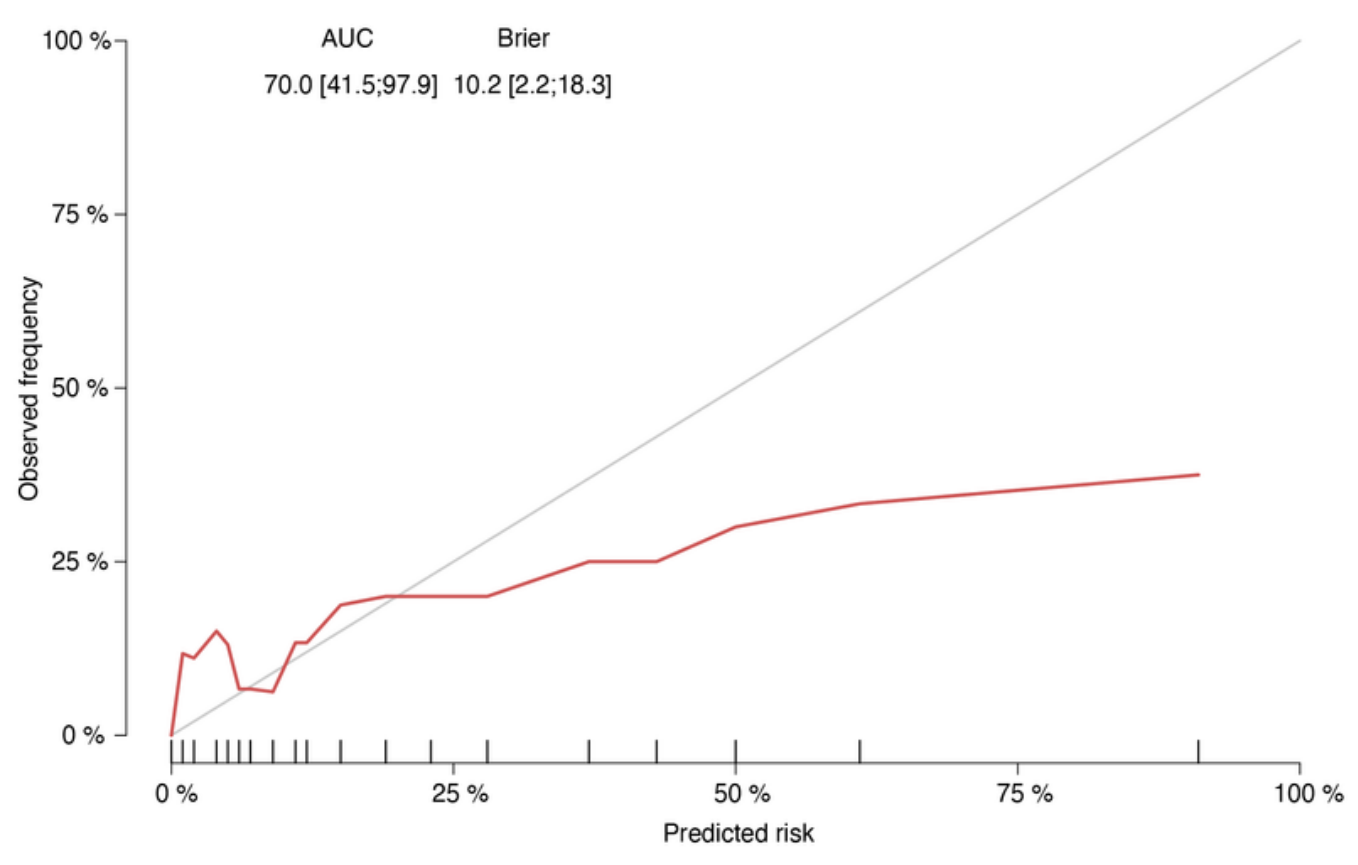

Figure 5 
External validation of the prediction of hematological malignancy bleeding events after CAR-T cell therapy using Nomogram in the validation cohort. A. Discrimination: area under the receiver operating characteristic (ROC) curve (AUC) of 0.72. B. Correction: calibration curve for predicting CAR-T-related bleeding events.

\section{Supplementary Files}

This is a list of supplementary files associated with this preprint. Click to download.

- Additionalfile1.docx

- Additionalfile1.docx

- Additionalfile1.docx

- Additionalfile2.docx

- Additionalfile2.docx

- Additionalfile2.docx

- Additionalfile3.doc

- Additionalfile3.doc

- Additionalfile3.doc

- table11.xlsx

- table11.xlsx

- table11.xlsx

- table21.xlsx

- table21.xlsx

- table21.xlsx

- table31.xlsx

- table31.xlsx

- table31.xlsx 